\title{
EXPOSURE TO VIOLENT AND PROSOCIAL VIDEO GAMES: EFFECTS ON HOSTILE ATTRIBUTION BIAS, AGGRESSION, AGGRESSIVE DRIVING TENDENCIES, AND EMPATHY
}

by

\author{
Jason A. Middleton, \\ Bachelor of Arts (Honours), York University, 2007
}

\author{
A thesis \\ presented to Ryerson University \\ in partial fulfillment of the \\ requirements for the degree of \\ Master of Arts \\ in the Program of \\ Psychology \\ Toronto, Ontario, Canada, 2014 \\ (C) Jason A. Middleton 2014
}




\section{AUTHOR'S DECLARATION FOR ELECTRONIC SUBMISSION OF A THESIS}

I hereby declare that I am the sole author of this thesis. This is a true copy of the thesis, including any required final revisions, as accepted by my examiners.

I authorize Ryerson University to lend this thesis to other institutions or individuals for the purpose of scholarly research.

I further authorize Ryerson University to reproduce this thesis by photocopying or by other means, in total or in part, at the request of other institutions or individuals for the purpose of scholarly research.

I understand that my thesis may be made electronically available to the public. 
Exposure to Violent and Prosocial Video Games: Effects on Hostile Attribution Bias,

\author{
Aggression, Aggressive Driving Tendencies, and Empathy \\ Jason A. Middleton \\ Master of Arts in Psychology, 2014, Ryerson University
}

\begin{abstract}
The present study aimed to investigate the possible relation between reported video game play (i.e., violent, aggressive driving, and prosocial types) and four outcomes of social behaviour: hostile attribution bias, aggression, aggressive driving tendencies, and empathy. A sample of 136 university students (67 males and 69 females), age 17 to $58(M=20.66)$, completed various self-report measures. Data were analyzed both in terms of the whole sample and separately according to participant sex. The results provide partial evidence that there are links between violent games and aggressive attitudes (i.e., physical, but not relational, aggression); aggressive driving games and aggressive driving tendencies/punitive attitudes toward a convicted driver; violent games and hostile attribution bias; and violent games and lower empathy ratings. No support was found for the link between prosocial games and higher empathy. Future research directions for research on video games effects are outlined.
\end{abstract}




\section{Acknowledgements}

I would like to acknowledge the following individuals, who have each influenced my graduate studies in one form or another. Chiefly, I would like to thank my advisor, Dr. Stephen Want, who has served as a role model, mentor, and teacher throughout my studies. His extensive commentary on many drafts of this thesis helped to shape the final product. I would also like to extend my gratitude to Dr. John Turtle, who provided valuable feedback during the review process. Furthermore, I wish to thank Dr. Tara Burke for her support and insight as a member of my examination committee. I am deeply indebted to the Social Sciences and Research Council of Canada, which partially funded my second year of graduate school. Lastly, I would like to thank my loving family and friends for giving me the inspiration and encouragement to succeed in my academic endeavours. 


\section{Dedication}

To my brother, Jerry, who encouraged me to pursue graduate school in the first place. 


\section{Table of Contents}

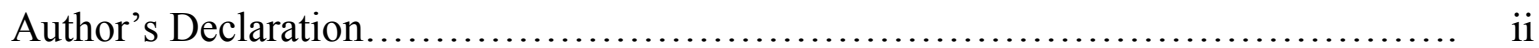

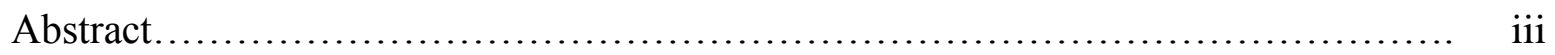

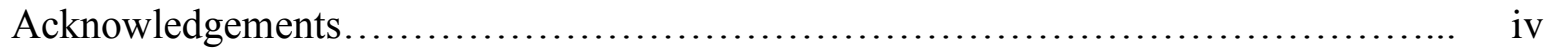

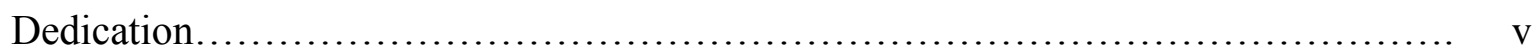

Table of Contents.................................................... vi

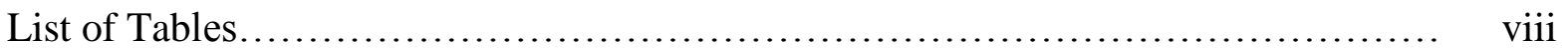

List of Appendices....................................................... ix

Chapters

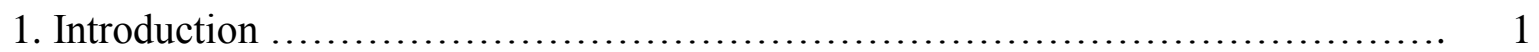

The History of Violent Media and "Moral Panics......................... 2

The Multi-Causal Nature of Aggression............................... 5

Theoretical Models Relevant to the Influence of Video Games............... 7

Experimental Evidence of the Effect of Violent Video Games on Players....... 10

Aggressive Driving and the Influence of Video Games.................... 16

Prosocial Effects of Video Games and Prosocial Behaviour.................. 20

Scepticism Concerning Media Effects on Consumers...................... 26

Gaps in the Literature and Overview of the Present Study.................. 27

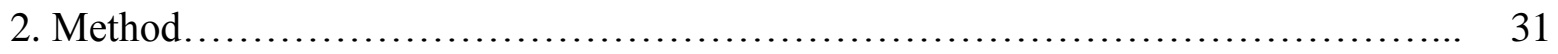

Participants................................................... 31

Measures........................................................ 31

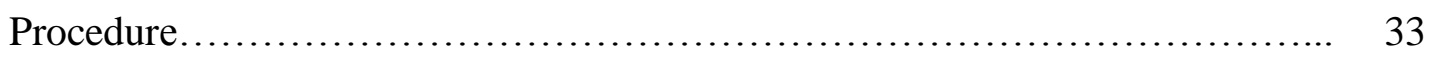

3. Results.............................................................. 35 
Preliminary Analyses................................................. 35

Main Analyses....................................................... 36

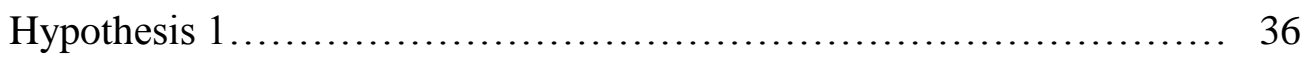

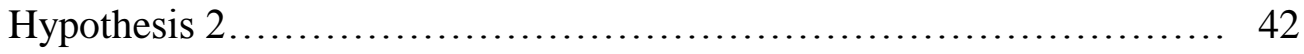

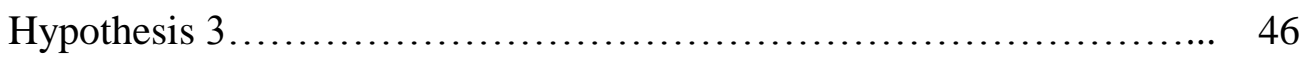

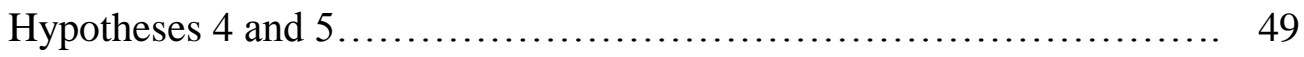

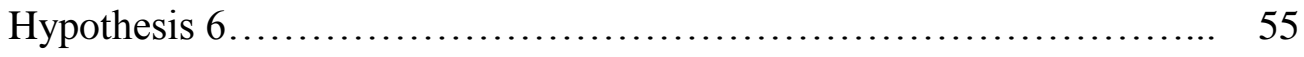

Video Game Effects among Lighter Users............................... 56

Summary of Results................................................. 57

4. Discussion................................................................. 59

General Findings......................................................... 59

The Present Results: Comparison with Previous Literature and Implications...... 61

Notes on Statistical Power and Statistical Analyses in the Present Study........ 63

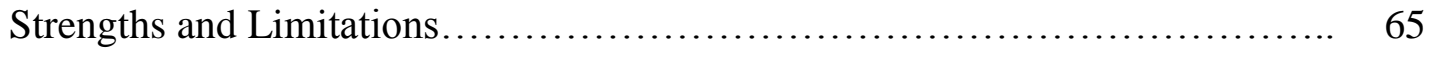

Future Directions for Research on Video Game Effects...................... 67

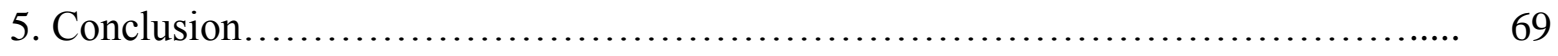

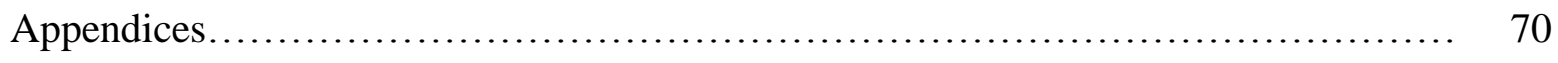

References.......................................................................... 82 


\section{List of Tables}

Table

Page

1 Proportion of Participants' Written Responses in Each of the Seven Categories for 39 Story Stem One (Getting Your New Shoes Dirtied)

2 Proportion of Participants' Written Responses in Each of the Seven Categories for Story Stem Two (Not Being Invited to the Party)

3 Proportion of Participants' Written Responses in Each of the Seven Categories for Story Stem Three (Having Your Parking Spot Stolen)

4 Proportion of Male and Female Participants Making Benign or Hostile Attributions in Story Stem Three (Having Your Parking Spot Stolen)

5 Proportion of Participant's Written Responses in Each of the Seven Unsympathetic Categories for Story Stem Four (Witnessing Someone Tripping and Falling)

6 Proportion of Participant's Written Responses in Each of the Seven Sympathetic Categories for Story Stem Four (Witnessing Someone Tripping and Falling)

7 Proportion of Participants Assigning a Prison Sentence in the Hypothetical Scenario Involving a Defendant Stealing a Car, Eluding Police, and Hitting a Pedestrian

8 Summary of the Statistically Significant \& Non-Significant Results for Each Hypothesis 


\section{List of Appendices}

Appendix

Page

A

Media Consumption Statistics for the Sample

B Demographic, Media Consumption, and Story Stem Questions

C Statistics for the Standardized Measures Used in the Present Study

77

D Subsidiary Hypotheses (Fictional Narratives and Parenting Style) 


\section{Introduction}

Since the beginning of the modern age of mass media, scholars have actively studied the influence that the media have on their wide audience of consumers. Many researchers who study media exposure (which includes exposure to television programs, newspapers, movies, and other forms of mass media) agree that the mass media can significantly influence their consumers. Perhaps the earliest systematic studies of links between media violence and aggression date back to the experimental investigations conducted by Albert Bandura, such as his famous "Bobo doll" study (Bandura, 1965). As Bandura did, many subsequent researchers have suggested that there is a relation between exposure to violent media and experiencing elevated levels of aggressive thoughts, feelings, and behaviours (see Anderson \& Bushman, 2001; Anderson et al., 2010; Paik \& Comstock, 1994 for meta-analyses). For instance, a study by Bushman and Anderson (2002) had participants play either a violent or nonviolent video game, and then complete a series of story stems that described an ambiguous situation with the potential to involve interpersonal conflict. In one scenario, participants read a story in which the protagonist's car is rear-ended by another driver at a stop light. Participants were then asked to list six things that the protagonist in the story might do, say, think, or feel. Participants who played the violent video game described the main character as behaving more violently, ruminating more about angry thoughts, and feeling angrier than did participants who played the nonviolent video game. Thus, in this study and in many others similar to it, participants' responses to self-report measures seem to indicate a greater propensity towards aggressive thoughts, feelings, and behaviours after exposure to violent video games. In addition, some researchers, such as Scharrer (2008), document a link between exposure to violent media and increased desensitization to violence, such that viewers who regularly consume a large amount of violent media possess less empathy than those who do not. On the other hand, some scholars have explored the idea that video games that involve 
acting to help, rather than hurt, others (e.g., City Crisis and Lemmings) can help foster empathy and prosocial behaviour (e.g., Gentile et al., 2009; Greitemeyer \& Osswald, 2010; Greitemeyer, Osswald, \& Brauer, 2010).

The principal aim of the present thesis is to explore the potential connection between video games and aspects of aggression, but also to investigate the possible link between prosocial video games and empathy. Since the association between violent video games and aggression is a contentious topic, it is pivotal to outline some caveats before highlighting the existing literature on this subject matter.

\section{The History of Violent Media and "Moral Panics"}

The influence of violent media on their consumers is controversial. As Ferguson (2008, 2010) mentions, alarm over violent video games might merely reflect the most recent of a series of "moral panics" over violent media content. To elaborate, in his book Savage Pastimes: A Cultural History of Violent Entertainment, Harold Schechter (2005) details how moral crusades over violent media have existed historically whenever a new medium was introduced to society. Take, for example, the medium of the film. In December 1911, Edwin Porter's film, The Great Train Robbery (1905), was believed by the general public and mass media to have influenced a young man, Fred Bishie, to commit a train robbery. Even though no concrete evidence existed to corroborate that Bishie had watched the film prior to committing his transgression, people were quick to attribute this man's behaviour to the viewing of the film. Schechter makes it clear that violence has been highly prevalent in various forms of mass media throughout history, and moral pandemonium over these new media was common. As but one example, Schechter quotes from the historian Russell Nye to illustrate the violent content of the dime novels, which were published by popular authors of the 1800s and the 1900s, such as Erasmus Beadle: 
In a similar vein, Russell Nye cites a typical passage from one of the later Beadle novels in which the hero - having stumbled upon "the swollen, mutilated corpse of a man, covered with blood and clotted gore" - notes how "the distorted countenance was rendered doubly repulsive by the red streaks where mingled blood and brains had oozed from the shattered skull.” (p. 34)

In addition to movies and the dime novels, people have voiced concern over other forms of mass media and other types of popular entertainment, including comic books, role-playing games (such as dungeons and dragons), and violent television shows. Therefore, video games are certainly not the first form of media to contain violence; the various forms of mass media have always contained violence, and concern over their effects is not a novel matter.

Scholars have long been interested in understanding the mechanisms of social influence on individuals, such as the mass media may exert, as well as possible mediators of such effects. One scholar, Carl Hovland, who researched the topic of persuasion, pointed out that war films (such as the Why We Fight series), which were aimed to increase solider morale, were effective in teaching soldiers factual information about war, but were not successful in improving their motivation to fight (Baumeister \& Bushman, 2014). Like Aristotle, Hovland argued that the efficacy of persuasion depends on other factors besides the medium of communication (i.e., film), such as who is delivering the message (e.g., the source; whether the source is perceived as credible and likeable), the content of the message (i.e., whether the message seems reasonable or strikes the recipient in an emotional way), and internal characteristics of the audience (e.g., age of the recipient; younger recipients, such as adolescents, may be more easily persuaded) (Baumeister \& Bushman, 2014). Joseph Klapper was another scholar who was fascinated by possible media effects on users. His theory of selective exposure maintains that the mass media does not directly influence consumers, but that it instead nourishes a user's predispositions. For 
example, a person who enjoys watching violent media may already be aggressive due to other factors apart from media violence exposure, such as affiliating with violent groups of peers (e.g., gangs), where group norms may condone violent behaviours (Klapper, 1960). Additionally, other scholars, such as Schechter (2005), argue that humans have been exposed to violent depictions of glorified violence throughout history, such as public executions, wrestling, and stonings. Altogether, early scholars were interested in the potential effects of media violence on users.

Granted that violence has permeated the mass media throughout history, it is plausible that previous forms of mass media have, in fact, exerted a small but significant effect on their consumers, such that consumers have shown slight increases in aggression compared to nonconsumers. However, since psychologists were not studying previous forms of mass media in an organized fashion, it is difficult to empirically verify whether, for example, the dime novels resulted in elevated rates of aggression among their readers. One exception to this argument, however, is violent television; much research has been conducted by psychologists that examines the effect of violent television on aggression, and meta-analyses confirm that viewing violent television is associated with small, though significant, increases in aggression among heavy consumers (Paik \& Comstock, 1994; although see Freedman, 2002 for prominent criticism of this research). Therefore, it does not seem unreasonable to suppose that playing violent video games may also be associated with small and significant increases in aggression. One of the goals of the present thesis is to explore that issue.

It is also the case that while violence is prevalent in several forms of mass media, the influence of video games in particular may be especially robust. Players of video games are more actively engaged in carrying out (virtual) violent acts than users of other forms of violent media, who merely read about or view such acts. Furthermore, while depictions of violence have existed among humans throughout history, video games in particular may constitute a recent and "rich" 
form of such portrayals of violence. Indeed, video games, unlike films and TV programs, provide users with direct reinforcement for carrying out virtual acts of aggression (Salem, 2010), and are becoming ever-more realistic and addictive as they evolve (Barlett, Harris, \& Baldassaro, 2007). Thus, violent video games may have the potential to have a particularly powerful influence on users' aggression. Therefore, despite the video game being far from the first form of mass media to contain violence, and not the first to raise concern over its potentially detrimental influence on consumers, there seems good reason to study the influence of video games on players.

\section{The Multi-Causal Nature of Aggression}

A second word of caution is in order regarding the study of video games and their effects on users. Any research which examines the relation between violent video games and aggression may be misconstrued as suggesting that a) violent video games are the only cause of aggression, and thus that b) aggression would not exist without violent video games. However, it is prudent to note that aggression, like most human behaviours, is governed by the law of multiple determinism; that is, aggression is stoked by multiple factors, and video games in particular may constitute just one reason why a particular user acts out in an aggressive manner. Thus, it is important to acknowledge from the outset of investigating the effects of violent video games on aggressive responses that video games alone are not entirely responsible for any user's aggressive behaviours. Instead, violent video games may be one of the factors that influence a person's tendency to respond aggressively.

It is also useful to distinguish here between ultimate and proximate bases of behaviour, which may help to shed some important light on how video games impact users. As outlined by Preston and de Waal (2002), Ernst Mayr was the first scholar to distinguish between proximate and ultimate causes of behaviour. According to Mayr, the proximate causes of an action involve factors in the organism's immediate environment (such as threat cues), whereas the ultimate 
causes are tied to evolutionary purposes (such as procreation and the passing on of one's genes). To help highlight the difference between the two, consider the question "Why do humans eat food?" The proximate causes of eating concern the specific time and place where someone is located when they eat; thus, when and what someone eats will, proximately, be shaped by satiety signals, the sights and smells of food, and the person's prior learning history of the reinforcing features of food (such as how it makes them feel). The ultimate causes of eating involve evolutionary factors, such as providing energy and nutrition for the body; an organism that did not eat would not survive, prosper, and pass on its genes to the next generation, so a drive to eat is pre-programmed in the organism.

Now consider the question "Why do humans commit acts of aggression?" The proximate causes of aggression are likely to include feelings of anger, frustration, the person's interpretational processes of provocative situations (such as their interpretation of others' behaviour as threatening or as benign), and their prior reward history for violent behaviours. The ultimate causes of aggression are likely to be evolutionary. It seems highly likely that our ancestors needed to possess at least some measure of an aggressive drive in order to have successfully competed both with other species and with members of their own kind. So, an aggressive drive would no doubt exist in the absence of violent video games; in other words, violent video games are clearly not the ultimate cause of aggression. However, it is precisely the proximate causes of aggression where violent video games may exert their effects.

A further analogy with eating may help to elaborate on this point. Consider the abundance, easy accessibility, and constant advertising of foods in the Western world that are high in fat and sugar content. Our desire for these very foods is unlikely to ultimately stem from their easy availability or the constant advertising of them. Instead, the ultimate causes of our desire for these foods stems from evolutionary factors - that, historically, high fat and sugary 
foods were a rarity in hunter-gatherer societies. However, the easy availability and constant exposure to the sights of such foods in advertisements may be proximate causes of their consumption. The fact that these foods are available in abundance affords people the opportunity to indulge in them, which, taken to the extreme, results in problems such as obesity. Similarly, violent video games are not the ultimate cause of humans' aggressive drives. However, the abundance of violent media forms, especially video games, allows consumers to indulge in their violent proclivities, which may affect the more proximate causes of aggression (such as violent thoughts and feelings, and the tendency to view others' actions as threatening rather than benign). In the final analysis, it is an open question whether indulging in violent forms of media, of which there appears to be no shortage, causes problems. This is the question that the present thesis is designed to address.

In light of the statistics indicating that video game usage amongst Canadians has doubled between 1998 (with about three percent of the population playing video games daily) and 2010 (with about six percent of the population playing video games daily; Statistics Canada, 2011), it is crucial that research continues to investigate this particular type of media. The aims of the present thesis are to explore the potential connections between exposure to video games (particularly violent, aggressive driving, and prosocial types) and three relatively underexplored outcomes: hostile attribution bias, aggressive driving, and empathy. In the following sections, the existing literature concerning the links between video games and these outcomes will be reviewed. First, though, a brief discussion of the theoretical mechanisms through which the mass media are believed to affect thoughts, feelings, and behaviour is presented.

\section{Theoretical Models Relevant to the Influence of Video Games}

Albert Bandura's social learning theory was one of the first theories to address the potential effect of the mass media on consumers. Bandura (1978) was primarily concerned with 
media influence on aggression, although his social learning theory can be extended to explain prosocial influences of the media as well. Bandura broadly defined aggression in the following manner: "Aggression is generally defined as behavior that results in personal injury and physical destruction" (p. 12). He went on to qualify that a behaviour is only considered aggressive when the attribution of the behaviour is perceived as intentional and meant to cause injury. Much of Bandura's research showcased the role that other individuals, or models, serve on young impressionable children. Bandura argued that aggressive actions can be acquired from three sources: the family, subculture, and mass media. Bandura cautioned that the role models presented by the mass media, who are all too often portrayed as aggressive characters, can heavily distort the viewer's knowledge and schemata about society and the world that they live in. According to Bandura's theory, the behaviours of models or idealized targets are emulated or mimicked by an individual and, over time, can become internalized. Indeed, video game players who model the actions and scenarios that they view on screen may learn several violent behaviours that, through repeated exposure, become internalized and begin to alter cognitive schemata and scripts.

Following on from Bandura, Bushman and Anderson (2002) created a theoretical model that helps to explicate the intricate processes involved in media effects on aggression. The General Aggression Model (GAM) sheds light on how video games dynamically influence their players. The GAM can be conceptualized as consisting of three stages: inputs, routes, and outcomes. Inputs are the biological, environmental, social, and psychological factors that influence aggression. They include a person's intrapsychic features, such as their trait levels of different cognitions, feelings, and physiological arousal, their beliefs and attitudes, and their cognitive and behavioural scripts regarding social situations. Inputs also include situational features, such as the levels of threat cues, provocation, frustration, and the incentives for 
aggression evoked by a specific situation. These inputs influence the person's "routes." Routes refer to the internal states within the person during a potentially aggressive encounter, such as their state of arousal, affect, and cognitions. A person's internal state, in turn, influences what are termed outcomes; these are the attributional processes or appraisals of the potentially aggressive event, which then motivate thoughtful actions (such as dismissing threat cues) or impulsive actions (such as initiating a heated altercation during a social encounter). In sum, the GAM proposes that the unique inputs of the person (e.g., the sex of the player and his or her personality traits) and the situation (e.g., frustration involved in the situation) shape the intrapersonal states of thought, feeling, and physiological arousal, which then influence the person's interpretation of the situation and their likelihood of behaving aggressively (Eastin \& Griffiths, 2009).

Over time, it is believed that exposure to violent video games can alter the intrapsychic features of some players (such that the player becomes, more generally, an aggressive person) by creating aggressive beliefs and attitudes, aggressive behavioural scripts, and expectations of aggression from others. As Bushman and Anderson conclude, repeated exposure to such violent video games can significantly alter cognitive scripts and schemata in a negative manner, which, undoubtedly, makes it harder to change these internalized attitudes once these cognitive dimensions are shaped. Therefore, according the GAM, video games have the potential to make a significant impact on a given player on a number of levels.

However, to view video games as having a solely destructive influence on their players is dismissive of the complexities inherit in many video games. Indeed, some researchers maintain that electronic video games can have both a good and a bad effect on the player (Southwell \& Doyle, 2004). On the one hand, violent video games can increase arousal, negative affect, and aggressive thoughts (Bushman \& Anderson, 2002), which, in turn, can shape users to interpret situations in a hostile way and behave more aggressively during their daily activities. On the 
other hand, Southwell and Doyle argue that certain video games may be teaching their users a number of positive and practical skills, such as interpersonal assertiveness, patience, increased visual attention, and critical thinking. Furthermore, there is research that supports the connection between playing prosocial video games and increased empathy (e.g., Greitemeyer, Osswald, \& Brauer, 2010). There is no theoretical reason why, if violent video games can prime violent thoughts, feelings, and actions, more prosocial video games should not be able to prime prosocial thoughts, feelings, and actions. In short, video games can be thought of as having the potential for both positive and negative effects on their users.

Since video games have the potential for both positive and negative effects, the following sections will elaborate on these influences. The influence of violent video games on increasing what is known as "hostile attribution bias," as well as decreasing empathy, is one topic that will be discussed. Furthermore, the influence of games which contain aggressive driving on thoughts related to aggressive driving will also be explored. Finally, as the present thesis will test for an influence of prosocial video games on empathy, this idea will also be detailed.

\section{Experimental Evidence of the Effect of Violent Video Games on Players}

Aggression and Hostile Attribution Bias. Meta-analyses by Anderson and Bushman (2001) and Anderson et al. (2010) support the link between playing violent video games and elevated aggressive behaviours among younger users (especially children and younger adults). Exposure to aggressive video games is also linked to elevated ratings of physiological arousal, aggressive-related affect, and violent cognitions (these effects hold true cross-culturally; see Anderson et al. for more detail). Furthermore, exposure to violent video games reduces prosocial behaviour in players.

As noted earlier, Bushman and Anderson (2002) documented a relation between playing violent video games and displaying a hostile attribution bias, which was evident in a player's 
responses to ambiguous story stems. According to these authors, "The hostile attribution bias is the tendency to perceive harmful actions by others as intentional rather than accidental" (Bushman \& Anderson, 2002, p. 1680). To elaborate, an individual who is said to have a hostile attribution bias would construe a harmful behaviour, such as a car rear-ending him or her, as an intentional action that was done on purpose, even though it may have occurred accidentally. They may then be more likely to respond to ambiguous situations with aggression, in response to what they perceive as aggression directed toward them. The research findings from these authors help to corroborate the GAM, whereby violent video game use produces a more negative interpretation of events (a hostile attribution bias), riskier decisions, and increased aggressive behaviour (Kirsh, Olczak, \& Mounts, 2005). Hostile attribution bias may thus play a key mediating role between exposure to violent video games and aggressive responses. If violent video games increase the likelihood that the behaviour of others will be seen as hostile, more hostile (i.e., more aggressive) responses to other people's behaviour are likely to be triggered. Since hostile attribution bias has been linked with increased aggressive responses (Gentile, Coyne, \& Walsh, 2011), it will be one focus of the present study. To date, one correlational study, two longitudinal studies, and one study in which exposure to violent video games was experimentally manipulated have examined whether exposure to violent video games is related to hostile attribution bias.

Krahé and Möller (2004) had grade eight students at selected German schools rate 25 listed video games in terms of frequency with which they played them and how much they enjoyed them. These games were rated for their level of violent content from one ("free of violent content") to five ("high level of violent content") by experts, and a composite measure of exposure to violent video game content was created (frequency $\mathrm{x}$ content). The students also completed a 15-item scale (based on the Normative Beliefs About Aggression Scale) to measure 
their attitudes toward physical aggression (seven items) and relational aggression (eight items). For instance, the students were asked to indicate on a scale from zero ("not at all okay") to three ("totally okay") the acceptability of physically aggressive acts (e.g., beating up a person who has made you mad) and relationally aggressive acts (e.g., spreading rumours about another person). The students also responded to ambiguous story stems in which two physical aggression and two relational aggression stories were used to tap hostile attribution bias. The physical aggression story stems portrayed a situation in which the intent of the harm-doer in the story was unclear, and wherein physical harm or property damage (a form of direct violence) was described (such as another person knocking over your belongings). The relational aggression story stems similarly depicted an ambiguous situation in which the harm-doer's intent in the story was vague, but here the potential harm was to reputation or respect (such as someone laughing when you are attempting to speak).

It was found that boys, relative to girls, played violent video games more and displayed a more profound hostile attributional style. That is, for the story stems, boys scored higher on perceived hostile intent (i.e., they viewed the ambiguous harmful actions as more intentional), desire to retaliate, and elevated anger ratings. They also expressed greater acceptance of physically-aggressive actions. Although there was no direct effect of violent video game playing on hostile attribution bias in this study, it did find an indirect effect. Greater exposure to violent video game content was linked to increased acceptance of aggression (i.e., perceiving aggression as a normal and acceptable response to a situation). This increased acceptance was, in turn, related to greater hostile attribution bias (i.e., perceiving greater hostile intent in the harmful actions of other people).

Möller and Krahé (2009) ran a longitudinal study of German adolescents to examine the link between violent video games, attitudes toward physical/relational aggression, and hostile 
attribution bias (all measured in a similar way to Krahé \& Möller, 2004). In this study, they also included a measure of self-reported aggression, which asked participants to state whether or not they had engaged in physical aggression (e.g., threats, hitting, biting) and relational aggression (e.g., spreading rumours or gossip). It was found that, at Time One of testing, boys scored significantly higher on exposure to violent video games than did girls. In addition, boys scored significantly higher on hostile attributional styles for vignettes tapping physical aggression, whereas girls scored significantly higher on hostile attributional styles for relational aggression story stems. At Time Two of testing (which was 30 months later), boys scored higher than girls in terms of using violent video games, acceptance of physical aggression, hostile attributions regarding the physical aggression story stems, and self-reported physical and relational aggression. Path analyses revealed that Time One exposure to violent video games significantly predicted the endorsement of aggressive norms, which predicted aggressive actions at Time Two. However, Time One exposure to violent video games did not directly predict hostile attributional style at Time Two. Instead, just as in their previous study (Krahé \& Möller, 2004), the effect of video games on increasing hostile attributional bias was indirect and mediated by endorsement of aggressive norms. In other words, playing violent video games increased the extent to which children viewed aggression as a normal and suitable response to potential threats and this, in turn, increased their tendency to view ambiguous incidents as motivated by hostile intent (i.e., their hostile attribution bias). Thus, this research supports the idea that exposure to violent video games (at Time One) can have a longitudinal effect on a user's hostile attribution bias (at Time Two), but this effect is mediated by norms supporting violence.

Gentile, Coyne, and Walsh (2011) conducted a longitudinal study on a sample of Minnesotan elementary school students in grades three to five. Among other measures used, these researchers had the students list their top three favourite video or computer games, 
television shows, and movies during two periods of data collection separated by a five-month time lag. Then, the students read a total of 10 story stems, four of which tapped physical aggression and six of which measured relational aggression. For each story stem, the measure of hostile attribution bias consisted of students' ratings of whether the intent of the harm-doer was benign or hostile, and whether their behaviour was done to be mean or not. The results indicated that males watched significantly more TV, and played more video games, than did girls. At both Times One and Two of assessment, it was found that exposure to media violence (from TV, video or computer games, and movies) was positively correlated with hostile attribution bias, as well as with composite measures of relational aggression and physical aggression (made up of self-, peer-, and teacher-reports of aggressive behaviours); exposure to media violence and prosocial behaviours were negatively correlated. Hostile attribution bias also showed a mediating effect with specific forms of aggression across participant sex; for boys, physical hostile attribution bias mediated the relation between exposure to media violence and physical aggression scores, whereas for girls, relational hostile attribution bias mediated the relation between exposure to media violence and relational aggression scores. Thus, this study helps to illuminate the way in which a hostile attribution bias mediates aggression in both males and females, though in different manners amongst the sexes.

Kirsh (1998) explored hostile attribution response styles to story stems after experimentally manipulating exposure to violent and nonviolent video games. In a sample of third- and fourth-grade children from a Kansas community, participants played either a violent or a nonviolent video game for 13 minutes. They then responded to (among other measures) five ambiguous story tasks, wherein they answered two questions pertaining to the harm-doer's intent, two questions about possible punishment and retaliation, and two questions about the emotional state of the harm-doer. Kirsh found that the children who played the extremely violent 
video game rated the ambiguous story stems more negatively (by perceiving the harm-doer's intent as more deliberate/done to be mean, by reporting a greater number of responses to retaliate, and by describing more negative emotions regarding how the harm-doer felt about the participant) compared to children who played the fairly nonviolent video game. These results provide further support that playing violent video games can indeed shape a hostile attribution response style in users.

Thus, to date, the existing evidence regarding the influence of violent video games on hostile attribution bias suggests that such games have either a direct or indirect influence, which acts to increase hostile attribution bias. An additional examination of this potential influence is one goal of the present thesis.

Desensitization and Dehumanization. Much of the research on violent video games corroborates their aggressive influences on their users. Violent video games can also shape their players to become desensitized to violence. An experimental study conducted by Bushman and Anderson (2009) verified this effect, wherein participants who were exposed to violent video games took much longer to help an injured confederate than did nonviolent video game players. In particular, the participants in this study were engaged in either a violent or nonviolent video game for 20 minutes. When the participant's time was up playing the video game, they were then administered an exhaustive questionnaire; some time into the questionnaire, a staged fight was enacted outside of the laboratory by the study's confederates, and the time it took for the participant to come out (or not) and help the "victim" was recorded. If the participant came out to help, they were then debriefed about the study. However, if the participant failed to leave the testing room, the experimenter then returned some time later and mentioned the staged fight to the participant, asking how serious the brawl was and if they had heard the affray. The study's results revealed that the players who had played violent video games took much more time to 
leave the testing room and aid the victim in the staged fight. Violent video game players also assessed the brawl as less serious, and were more likely to report not hearing the fight, than players who were exposed to nonviolent video games. As the authors remark, violent video games (and, in general, violent media) can have a desensitizing influence on their players in terms of numbing them to another person's suffering. This, in turn, can lead them to be less likely to act in a prosocial manner to those who are suffering.

Some researchers have empirically demonstrated that playing violent video games can lead players to feel increased dehumanization (Greitemeyer \& McLatchie, 2011), wherein, at least in the short-term, the player perceives other people as subhuman. For example, Greitemeyer and McLatchie found that participants who played a violent video game (Wolfenstein) were more likely than participants who played a neutral video game (3D Pinball) to deny that other people possessed uniquely human traits and emotions, such as the capacity for broadmindedness or hope. Some researchers further explicate the concept of dehumanization by mentioning that violent video games typically portray the villains (who are oftentimes human) as less than human (Greitemeyer \& McLatchie, 2011; Hartmann \& Vorderer, 2010). Thus, violent video games may motivate aggressive tendencies in their players by fostering dehumanization. Players of violent video games may become desensitized to violence against other people, and feel less empathy for them, because violent video games encourage users to perceive others as less than human.

\section{Aggressive Driving and the Influence of Video Games}

While many researchers have studied the influence of violent video games on general aggression, more recently, researchers have turned their attention to the relation between video game use and specific forms of aggression. One area of concern here has been the link between video game use and aggressive driving. Road Safety Canada Consulting (2011) describes aggressive driving as encompassing any of a number of behaviours, including driving through 
red lights, speeding, tailgating, repetitiously passing and manoeuvring around other vehicles, and dismissing another vehicle's right of way. Aggressive driving is best viewed on a behavioural continuum, from the mild forms of aggressive driving (which pose moderate risk), such as horn honking, through to the extreme, more criminal acts, as seen in so-called road rage (such as rearending another vehicle, which poses a high risk to the safety of both the victim and the offender) (e.g., Sharkin, 2004). Concern has been raised over the influence of video game use on aggressive driving because many modern video games contain episodes in which players are rewarded for engaging in precisely these particular acts.

There are a few studies which examine the relation between violent video games and aggressive driving, including Brizuela (2011), Bushman and Anderson (2002), and Fischer et al. (2009). Research by Bushman and Anderson (2002), described earlier, measured aggressive driving tangentially. To reiterate, participants in this study were asked to play either a violent or nonviolent video game, and to then complete a story stem in which the protagonist's car was rear-ended by another driver. The findings from this study established that participants who played a violent video game (relative to a nonviolent video game) responded more aggressively in terms of the thoughts, feelings, and actions that they attributed to the story stem protagonists. In particular, some of the commonalities in the violent video game players' responses included behavioural (e.g., kicking the other driver's vehicle, shooting or stabbing the other driver, and screaming and swearing at the other driver), cognitive (e.g., thinking that the other driver is "dead meat," a bastard, or should have a knife stabbed through their eye), and affective manifestations (e.g., feeling irritated, pissed off, and angered) of aggression. Although this study did not directly measure the overt behaviour of the participant while driving a vehicle, the results highlight the important link between playing violent video games and aggressive internal states (affect, arousal, and cognitions) in a driving scenario. 
Brizuela (2011) had 103 male participants first rate the extent to which they played Teenand Mature-rated video games, as well as video games rated as suitable for Everyone, in the past day, week, or month. Teen- and mature-rated video games were assumed to contain a greater amount of violent behaviours than games rated as Everyone. Then, the respondents were asked to rate the degree to which they would engage in a risky driving scenario, which was measured using the Propensity for Angry Driving Scale (PADS). The PADS presents the participant with a series of hypothetical driving scenarios (such as another driver stealing your parking space), and then asks the respondent to pick a response (out of four) regarding how they would react to the given driving situation. The responses vary with respect to the level of retaliation and negative emotion. It was found that the participants who played Mature-rated video games in the past day, week, or month scored higher on the PADS than participants who played games from other ratings (i.e., Everyone and Teen). Furthermore, the more Teen-rated video games that were played over the past day, the higher their scores were on the PADS. This research study provides preliminary evidence that supports a connection between exposure to violent video games and elevated ratings on an aggressive driving measure (that is high in reliability and validity).

Fischer et al. (2009) also studied the link between playing violent video games (specifically, exposure to racing games) and elevated aggressive responses (i.e., risk-taking), which is a phenomenon they call the "racing-game effect." In a series of four studies, participants played a high risk-taking (racing) or a non-risk-taking (neutral) video game. In Study One, participants from the University of Munich took part in a two-day study. On day one, the participants played either a racing game (Burnout, which rewards traffic violations, such as hitting pedestrians and driving on the sidewalk, to meet the objectives of the game) or a nonracing game (Tetris) for a period of half an hour. Following a period of 24 hours, on day two, participants were then administered the Vienna Risk Taking Test (WRBTV), which is a measure 
that presents the participant with various driving scenarios. The WRBTV first described each traffic situation in words, and then showed the actual driving scenario via video two times (in which the participant simply watched the video the first time and then, on a second viewing, rated the extent to which they considered the given driving manoeuvre to be risky). The longer the respondent waited to indicate that the driving manoeuvre was risky, the higher they scored on perceived risk taking. The results from this study revealed that after exposure to a risky driving video game (relative to a non-racing game), there was a persistent increase in risk taking, which was reflected by increased risk-taking scores on the WRBTV. Study Two revealed a similar pattern of results, with participants who had played a racing game (Need for Speed or Burnout) scoring significantly higher on the WRBTV (which was administered either immediately following game play or 15 minutes later) than participants who had played a neutral game (Tak or Tetris). Furthermore, participants who played a racing game perceived themselves as riskier drivers than did players who played a neutral video game. In Study Three, participants played a street-racing game (Need for Speed or Burnout, which, as already mentioned, reward traffic violations), a Formula 1 (F1) game ( $F 1$ or Imola, which reward accuracy and speed of manoeuvres over traffic violations), or a neutral video game (Tak or Tetris, which do not involve driving). The results showed that players who were exposed to the street-racing game scored significantly higher on perceived risk taking (as measured by the WRBTV) than did participants who were exposed to an F1 game or a neutral game. Furthermore, the results indicated that players who had played a street-racing game perceived themselves as "more risky" (as measured by rating on a Likert scale the extent to which eight phrases, which tapped perception of the self as a careless driver, applied to the participant, such as "I like to participate in street racing") relative to players who played a F1 or a neutral video game. Study Four assessed whether there were any differences in perceived risk-taking between players of violent video games and people 
who merely observed the video games. It was found that players who were engaged in streetracing video games, whereby they were actively violating traffic norms, displayed an elevated inclination of risk-taking, as well as a more favourable attitude toward risky driving, than did the observers of the racing and non-racing games, and the players of the non-racing video games. Thus, the findings from this study, as well as the previous studies, help to illuminate the specific types of video games which are linked to increased risk taking, namely video games which reward traffic violations.

There is clearly mounting evidence to suggest that exposure to violent video games is linked to elevated aggressive thoughts, feelings, and actions in general, but also that there are links between specific forms of violent video games (e.g., aggressive driving types) and specific forms of aggression (e.g., risky driving). However, what does the research document on the effects of prosocial video games and subsequent prosocial behaviours?

\section{Prosocial Effects of Video Games and Prosocial Behaviour}

Several different beneficial effects of video games have been proposed, such as teaching specific skills like typing (Wolf, 2001), improving hand-eye coordination (Johnson, 2006), and strengthening scientific (Steinkuehler \& Duncan, 2008) and logical (Johnson, 2006) habits of mind. Relatedly, research even shows that young children who watch prosocial television programs, such as Mister Rogers' Neighborhood, relative to neutral programs (e.g., nature documentaries), readily acquire prosocial content and imitate helping behaviour (Friedrich \& Stein, 1975). If one is to accept the premise that playing prosocial video games can induce prosocial behaviours, the next logical question is what does the empirical literature show?

Research by Salem (2010) examined the link between playing prosocial, violent, or neutral video games and subsequent ratings of empathy. According to Fraser et al. (2012), empathy is often used interchangeably with sympathy, which involves "...feeling bad for 
another's situation and acting on those feelings" (p. 639). Salem had participants play one of three video games (a prosocial one, Guitar Hero 3 Co-Op, a violent one, Super Mario Smash Bros. Brawl, or a neutral one, Wii Sports Bowling) with a partner for 20 minutes. Salem notes that prosocial video games are very difficult to define very broadly, as are aggressive driving video games. However, as Salem elaborates, Guitar Hero 3 Co-Op was considered a prosocial game because players had to cooperate with a partner who played the same game beside them, and the extent to which they cooperated determined whether or not they succeeded at the game. To measure empathy, which was assessed both before and after game play, Salem used three of the four subscales of the Interpersonal Reactivity Index (IRI): perspective-taking, empathic concern, and personal distress. Results indicated that the participants who played the prosocial video game reported a significant increase in empathy on the personal distress subscale of the IRI from pre- to post-test; participants who played the violent or neutral video game did not show the same effect. It was also found that players who were exposed to the neutral video game reported a significant increase in scores on the perspective-taking subscale; participants who played the prosocial or violent video game did not. Salem speculates that this latter research finding likely emerged because participants had breaks while playing the neutral game (unlike those who played the prosocial or violent games) to converse with their partners and empathize with them regarding game strategies and general feelings.

Gentile et al. (2009) provided cross-cultural evidence of the effect of playing prosocial video games on prosocial behaviours in a series of three studies. Their first study was a correlational, cross-section design that examined game play among a sample of Singaporean high school students. Prosocial behaviour was measured in several ways, including using items from the Prosocial Orientation Questionnaire (to assess helping behaviour and cooperation/sharing), the Children's Empathic Attitudes Questionnaire (to tap trait empathy), the 
Personal Strengths Inventory (to gauge emotional awareness), the Normative Beliefs About Aggression Scale (to measure approval of violence), and six ambiguous story stems to tap hostile attribution bias. Results from regression analyses revealed that, after controlling for the potential confounds of age, sex, quantity of time devoted toward playing video games weekly, and exposure to violent games, exposure to prosocial video games was positively associated with elevated rates of prosocial behaviours and traits. Conversely, exposure to violent video games was negatively associated with prosocial behaviours and traits. Their second study was a longitudinal design, which examined prosocial video game play among child and adolescent Japanese youth. Results revealed that the quantity of game play of prosocial video games at Time One of testing indicated the quantity of prosocial behaviours at Time Two of testing. In their third study, which was experimental, participants played a prosocial (Super Mario Sunshine or Chibi Robo), violent (Crash Twinsanity or Ty2), or neutral video game (Super Monkey Ball Deluxe or Pure Pinball) for 20 minutes. Super Mario Sunshine is prosocial in that Mario models helping behaviour, such as cleaning up the graffiti on the island he is on and saving Princess Peach; Chibi Robo rewards players with "happy points" for performing good deeds, such as cleaning the floors in the home where game play takes place. After game play, participants were then asked to assign 11 tangram puzzles (which involved manipulating seven different shapes to form a given outline) to another participant (partner) in the study, wherein they could choose from 10 easy, 10 medium, and 10 hard puzzles; if the partner completed 10 of the 11 puzzles after a 10 minute period, that partner would then get a 10 dollar gift card. The number of easy puzzles chosen by the participant was used to reflect helping behaviour, whereas the number of difficult puzzles chosen was indicative of harmful behaviour toward the partner. This study revealed that participants who were exposed to a prosocial video game scored significantly higher on helping behaviour (as indicated by assigning more easier puzzles to their partners) 
compared to participants who had played a violent or neutral video game. Furthermore, participants who played a violent video game scored significantly higher on harmful behaviour (as indicated by assigning more difficult puzzles to their partner) compared to players of the other video game types. The above three studies all testify to the positive link between playing prosocial video games and increased prosocial behaviours.

Greitemeyer, Osswald, and Brauer (2010) were also curious to verify the connection between playing prosocial video games, empathy, and schadenfreude (which is a German term referring to pleasure derived from another person's adversities). In their first experiment, participants played either a prosocial (Lemmings) or a neutral video game (Tetris) for a period of 10 minutes. Lemmings is considered a prosocial video game because the aim of the game is for players to save the lives of as many pixelated lemmings as possible (left to their own devices, the lemmings march to their deaths; the player can save them by safely guiding them away from water, lava, and other deadly traps). After game play, in addition to completing demographic data, a vignette of Paris Hilton was provided in which she was described as driving and getting caught while holding a suspended license (and the respondent was asked to rate their feelings of relief, schadenfreude, and happiness). The participant also read two student essays in which it was evident that the students who wrote the essays had suffered from an unfortunate event (such as breaking their leg in an athletic game), and the participants were then asked to rate the extent to which they felt compassionate, sympathetic, and soft-hearted toward the students who wrote the essays. It was found that, relative to the participants who played Tetris, the participants who played Lemmings scored significantly lower on schadenfreude and higher on interpersonal empathy. Regarding participant sex, females scored significantly higher on empathy ratings than did males. In their second experiment, participants played a prosocial video game (Lemmings), an antisocial video game (Lamers, which is a parody of Lemmings, whereby players aim to kill, 
rather than save, pixelated characters), or a neutral video game (Tetris). Compared to the other two games, playing the prosocial video game significantly elevated empathy ratings, yet playing the antisocial video game had no significant influence on empathy ratings relative to the neutral video game condition. The finding that playing the antisocial video games did not significantly influence empathy ratings may have emerged, as the authors speculate, due to the short duration of game play. In general, these studies corroborate the effect of playing prosocial video games on empathy (which is to increase it) and reported rates of schadenfreude (which is to reduce it).

Greitemeyer and Osswald (2010) examined the association between video game content, prosocial actions, and mood. In their first experiment, participants played a prosocial (Lemmings), antisocial (Lamers), or neutral (Tetris) video game for eight minutes; after eight minutes of game play, the experimenter "accidentally" dropped some pencils on the ground, and the time it took the participant to stand up and offer assistance, or not, was recorded. It was found that participants who had played the prosocial video game were significantly more likely to pick up the pencils that the experimenter "accidentally" dropped relative to the neutral or antisocial video game conditions. In their second experiment, it was discovered that participants who played a prosocial video game were significantly more likely to help out in future studies (in fact, all of the 20 participants acquiesced to such a request) and to devote more hours doing so compared to the neutral condition counterpart (in which only 13 of the 20 participants were willing to participate in future studies). Greitemeyer and Osswald's third experiment measured the extent to which a participant would intervene in a heated altercation between a vulnerable female experimenter and a harassing male confederate who had entered the room near the end of the experiment, posing as the experimenter's ex-boyfriend. This experiment revealed that 10 out of the 18 participants who played the prosocial video game intervened, whereas only four out of the 18 participants who had played the neutral video game intervened to help out the 
experimenter (even when controlling for likability ratings of the video game, gender, video game content, and mood of the participant). Their final experiment tapped the extent to which playing a prosocial or neutral video game influenced the thought processes of players, which was measured by having participants list the ideas that were flowing through their mind following game play. Results indicated that participants who played the prosocial video game reported significantly more prosocial thoughts (such as ruminating about saving the greatest number of "Lemmings" as one could while playing Lemmings) than those who played the neutral video game. The aforementioned studies further support a link between playing prosocial video games and elevated rates of empathic behaviour (in this case, helping out an experimenter pick up pencils, helping out in future experiments, and helping out a victim in need) and prosocial thoughts (in this case, a greater frequency of prosocial thoughts).

A longitudinal study exploring the connection between video game content, aggression, and empathy was conducted by Krahé and Möller (2010). A total of 1,237 students (51.5\% female) in various secondary schools in Germany were recruited for this study; data collection consisted of two stages, which spanned a twelve-month period. Measures included rating the frequency with which the participant consumed various genres of television programs, movies, and video games using a four-point Likert scale (which resulted in a score for media violence use and nonviolent media use), aggressive behaviour ratings using a four-point Likert scale (five items tapped physical aggression and five items tapped relational aggression), rating six items from the "affective empathy" subscale of the Basic Empathy Scale to measure empathy, grades earned in three core school-related subjects (Math, English, and German), and ratings of general media use regardless of content. Results concerning violent and nonviolent media usage indicated that boys, relative to girls, scored significantly higher on usage of violent and nonviolent media, as well as on both forms of aggression (i.e., relational and physical). However, 
girls rated significantly higher on the empathy items and earned higher grades relative to boys. It was also found that the greater the usage of violent media at Time One of assessment, the lower the ratings on the empathy items when tested at Time Two of testing. Additionally, there was a significant positive correlation, albeit weak, between exposure to nonviolent media and empathy scores. Put simply, greater usage of violent media was linked with lower empathy ratings; yet, nonviolent media exposure was weakly linked with higher empathy scores.

In sum, the literature suggests that exposure to prosocial video games is associated with increased helping behaviour, a greater number of prosocial thoughts, elevated interpersonal empathy, and reduced schadenfreude.

\section{Scepticism Concerning Media Effects on Consumers}

It is important to note that the scientific community is not unanimous in the belief that violent media affect users' aggression. Some researchers voice criticism regarding research on the detrimental effects of mass media on users. In his book Media Violence and Its Effect on Aggression: Assessing the Scientific Evidence, Jonathan Freedman (2002) reviews the empirical evidence which purports to support a link between media violence exposure (particularly television viewing) and aggression. Some of his primary criticisms of the research on this topic include the fact that youth violence has decreased considerably since the 1990s, measurement problems cloud the empirical findings (e.g., inappropriate measures of aggression are used in experiments; it also hard to accurately report how often video games are played), and that the findings from the studies in their entirety do not provide consistent evidence for an effect. Freedman also argues that other factors apart from media violence exposure may influence a person to be aggressive, such as lower socioeconomic status and prior criminal history. Relatedly, Christopher Ferguson $(2008,2010)$ points out similar issues with respect to media violence research. In fact, Ferguson argues that even violent video games may have prosocial 
effects on users. For example, even the controversial video game Grand Theft Auto, while violent in nature, requires the players to make choices (for better or for worse), and police presence suggests that antisocial behaviour will not be tolerated. Collectively, some researchers are critical of the effects of violent media exposure, including violent video games, on users.

\section{Gaps in the Literature and Overview of the Present Study}

From the above overview of the literature, it is evident that video games can have either prosocial or antisocial consequences, depending on their content. However, where the current literature is lacking is on the influence of violent video games on a specific form of aggression, which is aggressive driving. Therefore, the topic of aggressive driving attitudes, as they pertain to video game usage, is one issue that this thesis explored in some detail. The present study also investigated the potential relation between playing violent video games, displaying a hostile attribution bias, aggression, and rating lower on measures of empathy. In addition, as there is some research suggesting prosocial effects (especially that of increased empathy) of playing certain video games with prosocial themes, the present thesis also explored this link.

The following study used a self-report questionnaire, which asked the participants to freereport, and to select from two lists, which video games they have played. The two lists contained violent video games, such as Modern Warfare, video games that involve aggressive driving, such as Grand Theft Auto, and prosocial video games, such as Journey. Participants were also given an empathy measure, which was the Interpersonal Reactivity Index (IRI). Then, a series of four story stems were presented, which encompassed one physical aggression, one relational aggression, one aggressive driving, and one empathy story stem. Respondents were also asked to complete a single multiple choice question with three choices for each story stem to gauge the extent to which they believed the harm-doer in the story stem behaved accidentally, carelessly, or deliberately. For each story stem, respondents were asked to express how they would react to the 
given situation (see the Method section below). In addition, in order to distract participants from the focus on video games, other measures, such as a measure of personality, a measure of perceived parental control and support, and measures of TV watching and book reading, were included. In a cover story, participants were told that the purpose of the study was to explore relations between their personality (as assessed by the personality and empathy measures), their exposure to various fictional narratives (as assessed by the measures of TV, book, and video game exposure), and their own writing style (as assessed by their responses to the story stems).

In addition to bolstering the cover story, the inclusion of a measure of the extent to which participants read permitted a test of an additional hypothesis. In his book, The Better Angels of Our Nature: Why Violence Has Declined, Steven Pinker (2011) argues that reading fictional narratives may increase a reader's level of empathy, as they are endorsing the perspectives of other people (i.e., authors or fictional characters). Reading fictional stories compels the reader to fantasize about the moods, experiences, and events that the various characters encounter, which may help to strengthen the reader's interpersonal skills. There is only a small body of existing literature which examines the link between reading fictional narratives and increased empathy in readers (see Bal \& Veltkamp, 2013, for one recent example), and this thesis attempted to add to that literature. (In the interests of conserving space, and to retain the focus of the main document on the effects of video games, the analysis of this hypothesis is reported in Appendix D).

Finally, the inclusion of a measure of perceived parental control and support also enabled a test of an additional subsidiary hypothesis. Some prior research (Gomez \& Gomez, 2000; Gomez, Gomez, DeMello, \& Tallent, 2001) has demonstrated that low levels of perceived parental support (e.g., agreeing that one's primary caregiver "Did not help me as much as I needed"), coupled with high levels of perceived parental control (e.g., agreeing that one's primary caregiver "Tried to make me feel dependent of her/him"), are associated with the 
development of hostile attributional biases. By including a measure of perceived parental control and support (the Parental Bonding Instrument, or PBI; Parker, Tupling, \& Brown, 1979), this thesis provided an additional test of this link. (Again, in the interests of space and coherence of the thesis, this analysis is detailed in Appendix D).

The present study was novel in a number of ways. First, its measures of empathy, aggression (both physical and relational), hostile attribution bias, and attitudes toward aggressive driving were designed to be covert measures, such that participants would be less likely to identify the true dependent variables (i.e., the levels of aggressiveness displayed in their responses to the story stems) in the study. As few studies have used story completion tasks to measure aggression, hostile attribution bias, and empathy responses - except that of Bushman and Anderson (2002), described earlier - the present study aimed to add to the body of research demonstrating that story stems are a creative way to tackle the problem of demand characteristics (Orne, 1962). To help distract participants from the study's focus on aggression, and to test for empathic feeling, a story stem which gauged participants' level of empathy was used. Second, the present study measured two specific forms of aggression, which are physical and relational aggression, which may very well differ according to the sex of the participant. Third, the current literature which investigates the effects of video games on aggressive driving and hostile attribution bias is relatively sparse. Thus, the present thesis helps to provide important data on the effects of video games on both aggressive driving and hostile attribution bias. In short, the present thesis was novel in its efforts to use a covert measure of its dependent variables (hostile attribution bias, aggressive driving tendencies, and empathy), its goal to contribute to an inchoate research area, and it aims to measure different types of aggression, which are not always examined by researchers who study this topic. 
There were six hypotheses for the present study. The first hypothesis was that participants who reported playing a greater number of violent video games would respond to ambiguous story stems by describing more aggressive thoughts or actions than those who played relatively fewer violent video games. Second, it was hypothesized that participants who specifically reported playing aggressive driving video games would show a more pronounced (i.e., aggressive) response on the aggressive driving stem. The third hypothesis was that participants who reported playing a greater number of violent video games would demonstrate a more pronounced hostile attribution bias. This would be evident from their answers to the questions about story characters' motives (i.e., whether they perceived harmful actions as accidental, careless, or intentional). Fourth, it was hypothesized that participants who reported using a greater number of violent video games would score lower on the measures of empathy, as measured by the IRI and their responses to the empathy story stem. Fifth, it was hypothesized that participants who reported playing an increased number of prosocial video games would score higher on the measures of empathy, as measured by the IRI and their responses to the empathy story stem. Finally, an additional exploratory test of the influence of aggressive driving video games was conducted, looking for an effect of such games on participants' responses to a hypothetical case of aggressive driving. Here, it was hypothesized that participants who reported playing more aggressive driving video games would either a) demonstrate a more lenient attitude towards a convicted driver (i.e., give a less severe sentence in a scenario in which they were asked to hand down a punishment to an aggressive driver) or b) display a more punitive attitude towards a convicted driver (i.e., give a more severe sentence in this same scenario). 


\section{Method}

Participants. Participants were recruited from the undergraduate psychology student body at Ryerson University (i.e., students who were enrolled in an Introduction to Psychology course - PSY102 or PSY202), using the SONA recruitment database, which grants students a $1 \%$ credit toward their mark in their course for each hour of research participation in which they engage. The sample consisted of 136 participants (67 males and 69 females), with a mean age of 20.66 years $(S D=5.40)$ and a range of 17 to 58 years. All but six participants possessed a driver's license, which was assessed by self-report. Participants, on average, drove 11.56 days per month $(S D=10.54)$. Media consumption statistics for the sample, both overall and relative to participant sex, are in Appendix A.

Measures. The present study utilized a number of self-report measures. First, a demographic questionnaire asked participants to give some basic demographic data (including their sex, whether or not they possessed a driver's license, age, how many days per month they drove, and university major), to list up to four of their favourite video games, and to select from three tables whether they had heard of or played the listed video games (see Appendix B). They completed similar measures regarding books and TV programs. As previously mentioned, the inclusion of a measure tapping the number of fictional narratives read enabled a test of a subsidiary hypothesis (i.e., reading more fictional narratives would lead to higher empathy scores; see Appendix D).

Second, a personality inventory (the Neo Five-Factor Inventory-3; NEO-FFI-3; McCrae \& Costa, 2010) was used exclusively as a distractor measure to divert participants' attention from the topic of video games.

Third, an empathy measure (the Interpersonal Reactivity Index; IRI; Davis, 1980, 1983) was included in the questionnaire as a measure of empathic attitudes; the IRI has four subscales, 
which include fantasy, perspective-taking, empathic concern (which is of particular relevance to the present study), and personal distress. The empathic concern subscale is most directly related to true empathy, which is evident from the items on this part of the scale; virtually all items on this subscale gauge whether participants are emotionally touched by others who are less fortunate than they are. To elaborate on the IRI, the fantasy subscale gauges the degree to which a respondent identifies with fictional characters; a sample item includes, "I really get involved with the feelings of the characters in a novel." The perspective-taking subscale measures the degree to which a respondent spontaneously endorses another person's point of view; a sample item is, "I try to look at everybody's side of a disagreement before I make a decision." The empathic concern subscale taps the degree to which a respondent feels compassion, warmth, and concern for another person; a sample item is, "I often have tender, concerned feelings for people less fortunate than me." The personal distress subscale gauges the degree to which the respondent feels discomfort or anxious due to a negative experience of another person; a sample item is, "When I see someone who badly needs help in an emergency, I go to pieces."

Fourth, the participant rated their present mood on a five-point Likert scale using the Positive and Negative Affect Schedule (PANAS; Watson, Clark, \& Tellegen, 1988), which contains 20 words that describe 10 positive emotions (such as "interested") and 10 negative emotions (such as "hostile"). The PANAS was included as a measure in order to rule out the possibility that the participants' responses to the measures of aggression and empathy reflected their transitory, state levels of mood, rather than their more stable levels of these attributes.

Fifth, the participant completed the Parental Bonding Instrument (PBI; Parker, Tupling, \& Brown, 1979), which contains 25 statements that assess the extent to which their closest caregiver (i.e., mother or father) was caring (12 items, such as "Appeared to understand my problems and worries") and overprotective (13 items, such as "Tried to control everything I 
did"). Scores from the PBI allowed for a test of a second subsidiary hypothesis (i.e., participants who perceived their primary caregivers to be low on support, yet high on control, would demonstrate a more pronounced hostile attribution bias; see Appendix D).

Sixth, a series of four story stems were included in the questionnaire (see Appendix B), which asked each respondent to respond to one physical aggression, one relational aggression, one aggressive driving, and one empathy scenario. Like Kirsh and Olczak (2000, 2002), who studied the effects of violent comic books on social information processing, ambiguous story stems were deemed to be suitable tools to tap aggression and empathy. For each stem, respondents completed one multiple-choice question, which measured the degree to which they felt the targeted character in the story stem behaved accidentally, carelessly, or intentionally; this was the measure of participants' hostile attribution bias. They then completed a question for each scenario that was fairly open-ended (e.g., respondents answered, "What happens next? List six things you would do, say, think, or feel in this situation"), such that they could respond in whichever manner they felt appropriate; the extent to which participants wrote aggressive responses to the story stems was the measure of aggression.

Finally, a sentencing measure (adapted from Barlett, Harris, \& Baldassaro, 2007) was used to gauge the extent to which participants endorsed a lenient or punitive attitude towards a convicted driver. This measure presented the participant with a hypothetical scenario in which a defendant stole a car, eluded police, and hit a pedestrian. Assuming the role of judge, the participant was asked to select from one of five prison sentences a term that the defendant should serve, which ranged from least (i.e., probation) to most severe (i.e., a two-year prison sentence; see Appendix B).

Procedure. Data were collected from September 2013 to March 2014. Once the participant arrived at the lab, their informed consent was obtained (both verbal and written) and 
they were then told that they were taking part in a study about their exposure to fictional narratives, and the impact that this exposure has on their interpretation of stories. The participant was then directed to the testing room, where they were seated in front of a computer and asked to complete the entire questionnaire by entering their responses in the Qualtrics database. The questionnaire was divided into a number of sections, which included the following, in sequential order: 1) PANAS; 2) story completion task (i.e., the four story stems); 3) NEO-FFI-3; 4) IRI; 5) PBI; and 6) demographic and media consumption habits (i.e., video game play, television viewing, and reading fictional narratives). The questionnaire took about an hour to complete. When the participant finished the questionnaire, they were probed for suspicion and fully debriefed about the true nature of the study. 


\section{Results}

\section{Preliminary Analyses}

Summary statistics for the standardized measures used in the present study (i.e., the PANAS, NEO-FFI-3, IRI, and PBI) are provided in Appendix C. Hypothesis testing used onetailed tests because directional hypotheses were made, whereas all other analyses used two-tailed tests. In terms of the PANAS positive affect scores, males $(M=30.76, S D=8.14)$ scored significantly higher than females $(M=27.51, S D=7.74), t(134)=2.39, p=0.018$. However, there were no significant differences between males $(M=15.97, S D=6.08)$ and females $(M=$ 15.26, $S D=5.30$ ) on PANAS negative affect scores, $t(134)=0.73, p=0.469$. Regarding scores on the NEO-FFI-3, the only scale that was found to show significant differences between the sexes was agreeableness, whereby males $(M=24.39, S D=4.39)$ scored significantly higher than females $(M=21.48, S D=4.11), t(134)=3.99, p<0.001$. With respect to the subscales of the IRI, both the empathic concern and personal distress scale scores were significantly different between the sexes. In particular, males $(M=19.46, S D=4.82)$ scored significantly lower than females $(M=21.96, S D=3.83)$ on the empathic concern subscale, $t(134)=-3.35, p=0.001$. Additionally, males $(M=11.43, S D=4.39)$ scored significantly lower than females $(M=12.93$, $S D=4.29)$ on the personal distress subscale, $t(134)=-2.01, p=0.047$. While not significant, a trend towards significance between participant sex and scores on the fantasy subscale emerged, such that male scores $(M=17.76, S D=6.00)$ were slightly lower than female scores $(M=19.64$, $S D=6.29), t(134)=-1.78, p=0.077$. Finally, in reference to the PBI, there were no significant differences observed between the sexes (males: $M=27.55, S D=5.66$; females: $M=27.45, S D=$ 6.06) on either care scores, $t(134)=0.10, p=0.919$, or on overprotection scores, $t(134)=0.01, p$ $=0.989$ (males: $M=14.60, S D=6.44$; females: $M=14.58, S D=7.52$ ). 
For each of the hypotheses, analyses were run with both all of the cases overall and then separately according to participant sex. Prior to testing the hypotheses, it was believed that the participants' sex may serve as a potential confound in the statistical analyses. For instance, if males played more violent video games than females, and generally exhibited more of a hostile attribution bias (as seen in previous studies), then a statistical analysis between violent video game playing and hostile attribution bias scores for the entire sample of participants might reach significance due mainly to the differences between males and females. In this case, rather than concluding that violent video games contribute to hostile attribution bias, an alternative explanation would be that being male increases both hostile attribution bias and violent video game playing, independently of any connection between the two.

In fact, in the data for the present study, it was found that males reported playing more video games, regardless of type, compared to females. In particular, males $(M=10.10, S D=$ 7.22) reported playing significantly more violent video games than females $(M=4.09, S D=$ 4.78), $t(114.12)=5.71, p<0.001$. Furthermore, a significant difference was found in the number of aggressive driving video games played between males $(M=4.30, S D=2.66)$ and females $(M$ $=1.29, S D=1.66), t(110.15)=7.88, p<0.001$. Finally, males $(M=2.31, S D=3.22)$ reported playing more prosocial video games than did females $(M=1.38, S D=1.64), t(97.33)=2.13, p=$ 0.036. As the variance between males' and females' playing of video games was unequal, the degrees of freedom for the previous analyses were adjusted. Since males and females differed in their levels of empathy (as already discussed) and in their levels of aggression (as will be discussed), analyses are thus presented both as a whole sample and separately by participant sex.

\section{Main Analyses}

Hypothesis 1: Relation between Participants' Written Responses to Story Stems One (Physical Aggression) and Two (Relational Aggression) and their Game Playing Habits 
Here, the association between violent video game exposure and participants' written responses to both the first and second story stems is explored. This section endeavours to test the first hypothesis, which was that participants who reported playing more violent video games would score higher on aggression.

\section{Data reduction for written responses to story stem one (Physical Aggression}

Scenario). Each of the written responses for the first story stem was examined, and a subgroup of the responses which were most reflective of the modal answers provided by participants was then used to categorize the responses. After creating the subset of response categories, a convenience sample of eight people was utilized to see how they would rank order the responses from least to most aggressive. From the average of these orderings, the following seven categories of aggressive behaviour were created, in order from least to most aggressive:

(1) The participant's response did not convey any experience of anger (e.g., "It's okay though. ... I will not make my classmate feel guilty about the shoes; it's just shoes");

(2) The participant's response conveyed an experience of anger, but (s)he reported that they would not communicate or act on it (e.g., "I am quite mad that my shoes are now dirty. ... Make my way to the washroom to attempt to clean them; I would just be quiet and keep the problem to myself');

(3) The participant's response indicated that they would subtly communicate their anger to the other person by mumbling something under their breath, rolling their eyes, or giving the person a "look" or scowl (e.g., "I would give the person who bumped into me a dirty look");

(4) The participant's response suggested that they would swear out loud but not to the other person, say "Why didn't you watch where you are going?," "Really?," "Excuse me?," or "Are you serious?," ask the other person why they bumped into them, or tell the other 
person to be more careful or to watch where they are going (e.g., "Feel pissed; ask them why they did that in a hostile and aggressive tone");

(5) The participant's response signified that they would tell the other person that they ruined their shoes, would ask the other person for an apology, or would make a rude or sarcastic comment about the person (e.g., "Wait for an apology, or ask for one");

(6) The participant's response suggested that they would ask the other person to compensate them, ask them to clean their shoes, call them an idiot, or would yell/swear at the other person (e.g., "I would say, 'What the fuck?'; This person needs to pay to get these cleaned');

(7) The participant's response indicated that they would throw a fit, or push/hurt the other person (e.g., "I would be [sic] probably push back and let the other student know that it was not okay for them to do that because their action lead to my personal belonging[s] getting ruined").

Each participant's written response was categorized according to the highest (i.e., most aggressive) category behaviour that they had indicated (e.g., if they said they would give the person a look or scowl - level three - but equally relayed that they would yell/swear at the other person - level six - then they were categorized into level six). Two coders coded all 136 written responses, and their judgments agreed on 117 out of 136 responses (86\%); discrepancies were resolved via discussion. The proportion of participants classified into each of the response categories for story stem one is delineated in Table 1 on the following page.

Relation between video game playing and written responses to story stem one. To determine whether participants' responses to the first story stem reflected their transient mood, rather than more enduring aggression, correlations between their responses and their scores on the PANAS (both positive and negative affect scores) were examined. Non-parametric 
correlations (i.e., Spearman's rho) were run between the categories assigned to their written responses to story stem one and their positive affect scores, $r_{\mathrm{s}}=0.08, p=0.332$, as well as their negative affect scores, $r_{\mathrm{s}}=0.09, p=0.276$, which were non-significant.

Table 1. Proportion of Participants' Written Responses in Each of the Seven Categories for Story Stem One (Getting Your New Shoes Dirtied).

\begin{tabular}{lll}
\hline Response Category & $\begin{array}{l}\text { Number of Male } \\
\text { Participants }(n=67)\end{array}$ & $\begin{array}{l}\text { Number of Female } \\
\text { Participants }(n=69)\end{array}$ \\
\hline (1) No aggression & 5 & 14 \\
(2) Aggressive feelings (no communication/act on) & 12 & 21 \\
(3) Mumble, roll eyes, or give a look & 5 & 11 \\
(4) Swear aloud, ask why, or say watch it & 21 & 13 \\
(5) Say you ruined my shoes, ask for an apology, & 8 & 4 \\
$\begin{array}{l}\text { or make a rude/sarcastic comment } \\
\text { (6) Say you need to pay or clean the shoes, call }\end{array}$ & 11 & 5 \\
them an idiot, or yell/swear at them & & \\
(7) Throw a fit or push/hurt the other person & 5 & 1 \\
\hline
\end{tabular}

To delineate the relation between violent video game playing and participants' physical aggression responses, responses from the first story stem were correlated, using non-parametric (i.e., Spearman's) correlations, with both the total number of reported violent video games played and a composite (or intensity) measure of violent video game play (which was computed by multiplying the total number of violent video games played by the average number of hours per week of video game play). As a whole group, significant positive correlations were found between story stem one response categories (which were coded, categorically, from 1 to 7) and both the total number of violent video games that participants reported to have played, $r_{\mathrm{s}}=0.24$, $p=0.002$, as well as the composite violent video game variable, $r_{\mathrm{s}}=0.21, p=0.008$. Here, the pattern observed is that as the number of reported violent video games increases, both in terms of total number played and overall intensity, so do participants' scores on the story stem responses (which reflect more physical aggression). When the sample was split by sex, these same correlations were non-significant for both the total number of violent video games played, $r_{\mathrm{s}}=$ 
$0.10, p=0.201$ for males and $r_{\mathrm{s}}=0.14, p=0.131$ for females, as well as the intensity of violent video game play, $r_{\mathrm{s}}=0.02, p=0.436$ for males and $r_{\mathrm{s}}=0.18, p=0.075$ for females. Altogether, these results lend some support to the first hypothesis; that is, as a whole sample, there is a positive relation between physical aggression scores and playing violent video games (both in terms of number played and overall intensity). However, this relation is non-significant in the male and female subsamples.

\section{Data reduction for written responses to story stem two (Relational Aggression}

Scenario). A similar procedure to the first story stem was used to evoke a subgroup of representative response categories for the second story stem. The aggressive responses to this story stem generally embodied passive aggression (i.e., the experience of negative emotions that are conveyed in a covert way, such as by ignoring someone) or relational aggression (i.e., the experience of negative emotions that are conveyed in a less covert way, such as by distancing oneself from someone). The average of the response orderings produced the following seven categories of aggressive behaviour, which are ordered from least to most aggressive:

(1) The participant's response showed no evidence of anger, passive aggression, or relational aggression;

(2) The participant's response conveyed evidence of anger, but no passive or relational aggression;

(3) The participant stated that they would feel like their friendship with the other students in the story stem was limited, that the other students do not see them (i.e., participant) as a friend, or that they would ask about their colleagues' weekend plans to see if they mention the party;

(4) The participant relayed that they would make up an excuse to not go to the party in case they were invited or ask the other students why an invitation was not extended to them; 
(5) The participant indicated that they would make a sarcastic comment (e.g., "Gee, thanks for the invite!'), give the other students the cold shoulder (e.g., walk out past them without talking to them), or tell them they were throwing a bigger party;

(6) The participant wrote that they would hold a grudge, avoid them/distance him/herself from the other students in the future, not consider them friends anymore, or start to dislike them;

(7) The participant indicated that they would get even with the other students later (e.g., not invite them to something).

Table 2. Proportion of Participants' Written Responses in Each of the Seven Categories for Story Stem Two (Not Being Invited to the Party).

\begin{tabular}{lll}
\hline Response Category & $\begin{array}{l}\text { Number of Male } \\
\text { Participants }(n=67)\end{array}$ & $\begin{array}{l}\text { Number of Female } \\
\text { Participants }(n=69)\end{array}$ \\
\hline $\begin{array}{l}\text { (1) No aggression, either passive or relational } \\
\text { (2) Aggressive feelings, but no passive or }\end{array}$ & 24 & 19 \\
$\begin{array}{l}\text { relational aggression } \\
\text { (3) Friendship is limited, they don't see me as a } \\
\text { friend, or ask about weekend plans }\end{array}$ & 3 & 3 \\
(4) Make up an excuse or ask why no invite & 5 & 28 \\
$\begin{array}{l}\text { (5) Make a sarcastic comment, give cold } \\
\text { shoulder, or tell them you'll throw a bigger party }\end{array}$ & 5 & 11 \\
(6) Hold a grudge, dislike them, or avoid them & 7 & 1 \\
(7) Get even with them later & 1 & 6 \\
\hline
\end{tabular}

Like the first story stem, responses for this scenario were rank ordered relative to the highest category of aggressive behaviour that participants had endorsed. Two coders coded all 136 written responses, and their judgments agreed on 112 out of 136 responses (82\%). Table 2 above displays the proportion of participants that are categorized into each of the categories for story stem two.

Relation between video game playing and written responses to story stem two. Just like in the first story stem, Spearman's correlations were run between the categories assigned to 
participants' written responses to the second stem and their positive affect scores, $r_{\mathrm{s}}=-0.05, p=$ 0.567, as well as their negative affect scores, $r_{\mathrm{s}}=-0.07, p=0.425$, which were non-significant.

The association between violent video game play and participants' relational aggression responses were analyzed using Spearman's correlations. Amongst the whole sample, no significant relations were found between relational aggression response category (which were coded from 1 to 7 ) and either the total number of violent video games that participants reported to have played, $r_{\mathrm{s}}=0.01, p=0.452$, or the composite violent video game variable, $r_{\mathrm{s}}=0.06, p=$ 0.246. This non-significant finding was unexpected. When the sample was split by sex, these same correlations were non-significant relative to either the total number of played violent video games, $r_{\mathrm{s}}=0.04, p=0.385$ for males and $r_{\mathrm{s}}=0.08, p=0.266$ for females, or the composite violent video game variable, $r_{\mathrm{s}}=0.13, p=0.144$ for males and $r_{\mathrm{s}}=0.09, p=0.238$ for females. From these results, no support was found for a connection between relational aggression scores and violent video game play; thus, no additional support for the first hypothesis was found.

Altogether, partial support for the first hypothesis was found. A significant positive correlation was found between violent video game play (both in terms of number reported and overall intensity) and physical aggression scores amongst the entire sample of participants (yet not when participant sex was considered). This finding suggests that the more participants play violent video games, the higher they score on physical aggression feelings; however, participant sex is a potential confound in this association. No relation surfaced between violent video game exposure and relational aggression scores.

\section{Hypothesis 2: Relation between Participants' Responses to Story Stem Three (Aggressive Driving) and their Video Game Playing Habits}

In this section, the association between violent, as well as aggressive driving, video game play and participants' written responses to the third story stem are outlined. Relatedly, an effort 
is made to evaluate the second hypothesis, which was that participants who reported playing more aggressive driving video games would score higher on aggression on the third story stem.

\section{Data reduction for written responses to story stem three (Aggressive Driving}

Scenario). A similar procedure to that used on the first and second story stems was used to elicit a subgroup of representative response categories for the third stem. Seven response categories were created, and the average of these orderings, from least to most aggressive, was as follows:

(1) The participant's response contained nothing that indicated aggression (e.g., "I'd feel pretty disappointed. Probably just let it go after about a minute and find a new space somewhere else");

(2) The participant's response indicated that they would feel angry or aggressive, but they said that they would not act on that aggression (e.g., "I would become angry and very annoyed especially if there were not [sic] other spaces. There is obviously nothing I can do though, so I would likely not react to them in any given way");

(3) The participant said that they would swear under their breath, glare or stare at the other driver, or make a non-obscene gesture (e.g., roll their eyes or shake their head);

(4) The participant stated that they would honk their horn at the other driver, let the driver know they were waiting, ask the driver why they cut them off, or yell/swear at the other driver with the windows up;

(5) The participant relayed that they would get out of their car and tell the other driver to move, make an obscene gesture (e.g., raise their middle finger), or yell/swear at the other driver after rolling the window down;

(6) The participant indicated that they would get out of the car and confront or argue with the other driver, threaten them, or block them in with their own car; 
(7) The participant said that they would damage the other driver's car (e.g., "I would probably key their car" or "I would probably slash their tires") or fight the driver.

Like the first two story stems, the highest category behaviour that participants had indicated was used to classify responses. Two coders coded all 136 written responses, and their judgments agreed on 100 out of 136 responses (75\%). The proportion of participants categorized into each of the categories is given below in Table 3 .

Table 3. Proportion of Participants' Written Responses in Each of the Seven Categories for Story Stem Three (Having Your Parking Spot Stolen).

\begin{tabular}{lll} 
Response Category & $\begin{array}{l}\text { Number of Male } \\
\text { Participants }(n=67)\end{array}$ & $\begin{array}{l}\text { Number of Female } \\
\text { Participants }(n=69)\end{array}$ \\
\hline (1) No aggression & 3 & 1 \\
(2) Aggressive feelings (no communication/act on) & 2 & 5 \\
(3) Non-obscene gesture (mumble, roll eyes, or & 3 & 7 \\
give a look) & & \\
(4) Honk, let them know, ask why, or swear (self) & 22 & 36 \\
(5) Obscene gesture (give the finger, yell/swear) & 23 & 13 \\
(6) Confront, threaten, or block in the driver & 8 & 6 \\
(7) Violence (damage car or fight the driver) & 6 & 1 \\
\hline
\end{tabular}

Relation between video game playing and written responses to story stem three. As with the first two story stems, Spearman's correlations were run between the categories assigned to participants' written responses to the third stem and their positive affect scores, $r_{\mathrm{s}}=0.09, p=$ 0.280, as well as their negative affect scores, $r_{\mathrm{s}}=0.10, p=0.260$, which were non-significant.

The link between violent video game play and participants' aggressive driving responses (which were coded from 1 to 7) were analyzed using Spearman's correlations. As a complete group, significant correlations were found between participants' aggressive response category and both the total number of violent video games played, $r_{\mathrm{s}}=0.22, p=0.005$, and the composite violent video game variable, $r_{\mathrm{s}}=0.24, p=0.002$. These results suggest that the greater the number and intensity of reported violent video game play, the higher the participants' feelings of aggression in response to the driving scenario. When the sample was split by sex, these same 
relations were significant for males in terms of both the total number, $r_{\mathrm{s}}=0.28, p=0.010$, and intensity of violent video game play, $r_{\mathrm{s}}=0.28, p=0.012$. However, for females, no significant associations were found relative to either the total number of violent video games played, $r_{\mathrm{s}}=-$ $0.03, p=0.420$, or the intensity of violent video game play, $r_{\mathrm{s}}=0.02, p=0.423$. Thus, in terms of reported violent video game play, significant links with scores on the aggressive driving story stem were found amongst the entire sample, but this trend seems to be driven mainly by an effect among the male participants.

Separately from participants' violent video game play, Spearman's correlations were also computed between aggressive driving video game play (both in terms of number and intensity) and participants' aggressive responses to the driving scenario. Amongst the whole group, significant correlations were found between participants' aggressive response category and both the total number of reported aggressive driving video games played, $r_{\mathrm{s}}=0.22, p=0.006$, as well as the intensity of aggressive driving video game play, $r_{\mathrm{s}}=0.24, p=0.003$. Accordingly, the pattern here is that as participants reported playing more aggressive driving video games, both in terms of number played and overall intensity, their scores on the driver aggression story stem also increased. Splitting the sample by sex, for males, these same relations were significant using the composite aggressive driving variable, $r_{\mathrm{s}}=0.23, p=0.029$, but not the total number of reported aggressive driving video games played, $r_{\mathrm{s}}=0.14, p=0.139$. For females, these same correlations were non-significant in terms of either the total number of reported aggressive driving video games played, $r_{\mathrm{s}}=0.05, p=0.356$, or the composite aggressive driving variable, $r_{\mathrm{s}}$ $=-0.01, p=0.454$. In sum, the pattern that emerged from these analyses is that as participants (regardless of sex) reported playing more aggressive driving video games, their scores on the driver aggression scenario increased (i.e., demonstrated greater aggression); yet, this result is likely driven by an effect among males. 
Overall, significant links were found between violent, as well as aggressive driving, video game play (both in terms of number and intensity) and higher aggression ratings on the driving scenario for the whole sample. However, this effect seems to be present only among the male participants. Thus, some support for the second hypothesis was found.

\section{Hypothesis 3: Relation between Video Game Playing and Hostile Attribution Bias}

For each of the first three story stems, participants were asked to make a (forced-choice) attribution to the story character that produced the harmful action (see Appendix B). In each case, they had to choose between a clumsy or careless (unintentional or benign) attribution and a rude or mean (intentional) attribution. The extent to which participants chose the intentional attribution was the measure of hostile attribution bias.

Unfortunately, for story stems one and two, very few participants chose the intentional (hostile) attribution ( 1 of 136 for story stem one and 4 of 136 for story stem two), meaning that an analysis of the relation between hostile attributions and video game playing was not possible. However, responses for story stem three were sufficiently variable to permit analysis (58 of 136 participants chose the hostile attribution bias in this scenario). Hostile attribution bias for this particular scenario was measured by asking the participant to select why they believed the other driver took their parking spot (and they could pick from one of three responses, which were "The driver didn't notice that you were waiting to park in that spot," "The driver was being thoughtless and didn't think that taking the parking spot would be a big deal," or "The driver was being rude and deliberately took your spot, knowing how annoyed it would make you feel;" see Table 4 on the following page). If participants selected either of the first two responses, then they were classified as choosing a benign attribution; if they selected the last response, then they were categorized as endorsing a hostile attribution. Male participants were significantly more likely than female participants to make a hostile attribution (response 3 from Table 4) as opposed to a 
benign attribution (responses 1 and 2 ), $\chi^{2}(1)=10.69, p=0.002$. As such, coupled with the fact that male participants played more violent video games on average than did female participants, participant sex would confound the results of an analysis on the whole sample. Thus, alongside analyses using the whole sample, associations between violent/aggressive driving video game playing and attribution style were conducted separately by participant sex.

Table 4. Proportion of Male and Female Participants Making Benign or Hostile Attributions in Story Stem Three (Having Your Parking Spot Stolen).

\begin{tabular}{lll}
\hline Attribution & $\begin{array}{l}\text { Number of Male } \\
\text { Participants }(n=67)\end{array}$ & $\begin{array}{l}\text { Number of Female } \\
\text { Participants }(n=69)\end{array}$ \\
\hline $\begin{array}{l}\text { (1) The driver didn't notice that you were waiting } \\
\text { to park in that spot (Benign Attribution) }\end{array}$ & 8 & 12 \\
$\begin{array}{l}\text { (2) The driver was being thoughtless and didn't } \\
\text { think that taking the parking spot would be a big } \\
\text { deal (Benign Attribution) }\end{array}$ & 21 & 37 \\
$\begin{array}{l}\text { (3) The driver was being rude and deliberately } \\
\text { took your spot, knowing how annoyed it would } \\
\text { make you feel (Hostile Attribution) }\end{array}$ & 38 & 20 \\
\hline
\end{tabular}

Regarding violent video game play, as a whole sample, a trend towards significance was found between the total number played and attribution style, benign attribution: $M=6.36, S D=$ 6.76; hostile attribution: $M=7.98, S D=6.78, t(134)=-1.38, p=0.085$. This same relation was non-significant in terms of the intensity of play $(p=0.413)$. When analyses were conducted separately by participant sex, unexpectedly, males who made a hostile attribution (response 3 from Table 4) played fewer violent video games $(M=8.95, S D=6.69)$ than did males who made a benign attribution (responses 1 or 2 from Table $4 ; M=11.62, S D=7.72$ ), although this trend only approached significance, $t(65)=1.52, p=0.067$. As to the intensity of play, also unexpectedly, males who made benign attributions $(M=129.12, S D=148.38)$ scored significantly higher than did males who made hostile attributions $(M=65.47, S D=108.93)$, but this finding violated the homogeneity of variance assumption, $t(49.44)=1.94, p=0.029$. Thus, as the variances were different between the two attribution style groups, care should be taken in 
interpreting this finding. As to the female participants, those who made a hostile attribution reported playing a greater number of violent video games $(M=6.15, S D=6.74)$ than did those who made a benign attribution $(M=3.24, S D=3.46)$, but this effect violated the homogeneity of variance assumption, $t(23.19)=-1.83, p=0.040$. Concerning intensity of game play, females who made benign attributions $(M=10.78, S D=24.96)$, relative to hostile attributions $(M=$ $24.70, S D=41.57$ ), appeared to score lower, but this effect was not statistically significant and there, too, heterogeneity of variance was present, $t(24.91)=-1.40, p=0.088$. (Where heterogeneity of variance was present in the aforementioned analyses, the degrees of freedom were accordingly adjusted). Thus, as to violent video game play and attribution style, a trend towards significance was found using the total number played for the whole sample. When considering participant sex, the effect seemed to run in opposite directions; among males, more violent video game play was linked with lower hostile attribution bias, whereas among females, more violent video game play was linked with greater hostile attribution bias.

Similar analyses were run using the total number of aggressive driving (as opposed to violent) video games played and the associated composite variable. As a whole sample, there were significant differences between the two attribution response style groups and their reported playing of aggressive driving video games. Specifically, participants who endorsed benign attributions $(M=2.32, S D=2.52)$ played significantly fewer aggressive driving video games (total number) than did those who harboured hostile attributions $(M=3.38, S D=2.78), t(134)=$ -2.32, $p=0.011$. However, for the composite variable, no significant differences were seen between participants making benign $(M=15.98, S D=27.97)$ versus hostile attributions $(M=$ 17.47, $S D=33.24), t(133)=-0.28, p=0.390$. Splitting the sample by sex, there were no significant effects observed. Amongst males, participants who made benign attributions $(M=$ 4.38, $S D=2.64)$, relative to hostile attributions $(M=4.24, S D=2.72)$, did not play a 
significantly greater number of aggressive driving video games, $t(65)=0.22, p=0.415$. Similarly, male participants who made benign $(M=36.16, S D=35.73)$, compared to hostile $(M$ $=23.89, S D=38.94)$, attributions did not score significantly different on the intensity of aggressive driving game play, $t(65)=1.32, p=0.096$. Amongst females, these same relations were non-significant using either the total number (benign, $M=1.10, S D=1.42$, versus hostile attributions, $M=1.75, S D=2.12, t(67)=-1.48, p=0.072$ ) or intensity variables (benign, $M=$ 3.79, $S D=10.08$, compared to hostile attributions, $M=5.25, S D=11.04, t(66)=-0.53, p=$ 0.300). In short, some support for the third hypothesis was found. As a whole sample, participants who made hostile, rather than benign, attributions played significantly more aggressive driving video games. However, this relation was not significant in either sub-group of participants (males or females), suggesting that the overall effect was driven by the fact that males generally played more aggressive driving video games and exhibited more of a hostile attribution bias than females.

\section{Hypotheses 4 and 5: Relation between Participants' Empathy (their responses to Story} Stem Four - the Empathy Scenario - and their scores on the IRI) and their Gaming Habits

Here, the link between video game playing habits and participants' feelings of empathy, as measured by their written responses to the fourth story stem and their scores on the IRI, is investigated. An attempt is made to test the fourth and fifth hypotheses, which stated, respectively, that participants who reported playing more violent video games would score lower on empathy and that playing more prosocial video games would lead to higher empathy scores.

Data reduction for written responses to story stem four (Empathy Scenario). Like the other three story stems, a subset of the participants' written responses was chosen that reflected the most representative answers that participants had written and a convenience sample was asked to arrange these responses from least to most (un)sympathetic. Responses were 
ordered based on the extent to which they reflected an unsympathetic response (e.g., the participant thought the fallen person got what they deserved, laughed at them, or thought they were stupid) as well as a sympathetic response (e.g., the participant said they would ask the fallen person if they were alright, needed help, or would call paramedics if required). Seven response categories were created for the extent to which the participant's response was unsympathetic (coded from 0 to -6 , with lower values reflecting more unsympathetic feeling), which are outlined below:

(-6) The participant stated that they would laugh at the fallen person, think about stealing their phone, tell them that they are stupid/it is their fault, or say "Have a nice trip?";

(-5) The participant indicated that they would tell the other person to be more careful, to pay more attention, or would feel pleased that the other person got what they deserved;

(-4) The participant relayed that they would think it was the other person's fault, that they got what they deserved, "what a loser," or that they are stupid;

(-3) The participant wrote that they would pretend not to notice, walk on, or think it was funny;

(-2) The participant stated that they would think the other person should not walk/text concurrently;

(-1) The participant wrote that they would think "I'm glad it wasn't me";

(0) The participant's response indicated no apparent unsympathetic feeling.

In addition to the unsympathetic feeling, seven response categories were used to reflect sympathetic feeling (coded from 1 to 7 , with higher values indicating greater sympathetic feeling), which included the following:

(1) The participant's response suggested no apparent sympathetic feeling;

(2) The participant wrote that they would smile at the other person or feel sorry for them; 
(3) The participant relayed that they would make a light-hearted joke to reduce the other person's embarrassment, ask them if their phone is OK, or look to see if they are OK;

(4) The participant said they would pick up the other person's phone or ask them if they are $\mathrm{OK}$

(5) The participant wrote that they would help to fix the other person's phone or offer their help;

(6) The participant indicated that they would help the other person up;

(7) The participant stated that if the other person was hurt, they would stay with that person until medical help arrived, offer to take them to the hospital, or offer to call 9/11 for help.

Tables 5 (Unsympathetic Coding) and 6 (Sympathetic Coding) on the following page present the frequency of participants categorized into each of the categories. For the sympathy ratings, agreement was reached on 124 out of 136 responses $(91 \%)$ between the two coders. For the unsympathetic ratings, agreement was very high, with 130 out of 136 responses matching (96\%).

\section{Relation between violent video game playing and written responses to story stem}

four (Unsympathetic Ratings). Like earlier analyses, to evaluate whether participants' unsympathetic responses to the empathy story stem reflected their transient mood, rather than more enduring unsympathetic feeling, Spearman's correlations were run between the categories assigned to their written responses to the story stem (i.e., the unsympathetic categories; see Table 5) and their positive affect scores, $r_{\mathrm{s}}=-0.13, p=0.139$, as well as their negative affect scores, $r_{\mathrm{s}}$ $=-0.02, p=0.836$, which were non-significant.

Collectively, while no signification relation appeared between the total number of violent video games that participants (as a whole sample) reported to have played and unsympathetic scores on the fourth story stem, $r_{\mathrm{s}}=-0.05, p=0.291$, a trend towards significance was found using the composite violent video game variable, $r_{\mathrm{s}}=-0.13, p=0.061$. Here, the finding suggests 
that as participants' responses become more unsympathetic (i.e., their scores become more negative), the intensity of violent video game play increases. When the data were split by sex, these same relations were non-significant. For males, no significant effect was found using either the total number, $r_{\mathrm{s}}=0.09, p=0.230$, or intensity of violent video game play, $r_{\mathrm{s}}=-0.09, p=$ 0.235. Likewise, amongst females, non-significant correlations were found using the total number of reported violent video games played, $r_{\mathrm{s}}=-0.06, p=0.314$, and the composite violent video game variable, $r_{\mathrm{s}}=-0.08, p=0.271$. Altogether, virtually no support for the fourth hypothesis was found regarding the effect of violent video game playing on the unsympathetic response scores on the empathy story stem.

Table 5. Proportion of Participants' Written Responses in Each of the Seven Unsympathetic Categories for Story Stem Four (Witnessing Someone Tripping and Falling While Texting).

\begin{tabular}{lll}
\hline Response Category* & $\begin{array}{l}\text { Number of Male } \\
\text { Participants }(n=67)\end{array}$ & $\begin{array}{l}\text { Number of Female } \\
\text { Participants }(n=69)\end{array}$ \\
\hline (-6) Laugh, think to steal phone, say their fault & 3 & 2 \\
(-5) Tell them to be more careful; feel pleased & 18 & 16 \\
(-4) Think it's their fault; they're stupid/a loser & 9 & 10 \\
(-3) Pretend not to see, walk on, think it's funny & 16 & 9 \\
(-2) Think he should not walk/text concurrently & 6 & 9 \\
(-1) Think I'm glad it wasn't me & 0 & 1 \\
(0) No unsympathetic feeling apparent & 15 & 22
\end{tabular}

*The categories are numerically listed in descending order, from most to least unsympathetic.

Table 6. Proportion of Participants' Written Responses in Each of the Seven Sympathetic Categories for Story Stem Four (Witnessing Someone Tripping and Falling While Texting).

\begin{tabular}{lll}
\hline Response Category* & $\begin{array}{l}\text { Number of Male } \\
\text { Participants }(n=67)\end{array}$ & $\begin{array}{l}\text { Number of Female } \\
\text { Participants }(n=69)\end{array}$ \\
\hline $\begin{array}{l}\text { (1) No sympathetic feeling apparent } \\
\text { (2) Smile at him or feel sorry }\end{array}$ & 2 & 2 \\
(3) Joke with them to reduce embarrassment, ask if & 2 & 1 \\
phone is ok, or see if they're ok & 3 & 4 \\
(4) Pick up phone or ask if they're ok & 12 & 17 \\
(5) Help to fix phone or offer them help & 11 & 9 \\
(6) Help him up & 18 & 23 \\
(7) Stay with him, offer to take to hospital, or offer & 19 & 13 \\
to call 9/11 or someone else & &
\end{tabular}

\footnotetext{
*The categories are numerically listed in ascending order, from least to most sympathetic.
} 


\section{Relation between violent video game playing and the empathic concern subscale of}

the IRI. Another measure of empathy that was used to assess the fourth hypothesis was participants' scores on the empathic concern subscale of the IRI. As a whole sample, while no significant association (i.e., Pearson's) was found between the total number of violent video games played and scores on the empathic concern scale, $r=-0.07, p=0.216$, a significant negative relation emerged using the composite violent video game variable, $r=-0.15, p=0.042$. This latter result suggests that the greater the intensity of violent video game play, the lower that participants score on the empathic concern subscale. When the sample was split by sex, no significant correlations were detected. For males, the link between the total number of violent video games that they reported to have played and their scores on the empathic concern subscale was not significant, $r=0.06, p=0.319$. Also, amongst males, this same correlation using the composite violent video game variable was non-significant, $r=-0.06, p=0.327$. With respect to the female participants, a non-significant relation was observed between scores on the empathic concern subscale and the total number of violent video games that they reported to have played, $r$ $=0.08, p=0.266$, as well as with the intensity of violent video game play, $r=-0.06, p=0.303$. In short, as a whole sample, a negative relation was found between the intensity of violent video game play and scores on the empathic concern subscale of the IRI. Yet, when considering participant sex, these relations were non-significant and the magnitude of these relations was virtually zero. Some limited support for the fourth hypothesis has been found.

\section{Relation between prosocial video game playing and written responses to story stem}

four (Sympathy Ratings). To test whether participants' sympathetic responses to the empathy story stem reflected their transient mood, rather than more enduring empathy, Spearman's correlations were run between the categories assigned to their written responses to the story stem 
(i.e., the sympathetic categories; see Table 6) and their positive affect scores, $r_{\mathrm{s}}=0.14, p=$ 0.104, as well as their negative affect scores, $r_{\mathrm{s}}=-0.02, p=0.801$, which were non-significant.

Using the entire sample, there were no significant associations found between sympathy scores on the empathy stem and either the total number prosocial video games that participants reported playing, $r_{\mathrm{s}}=0.09, p=0.155$, or the composite prosocial video game variable, $r_{\mathrm{s}}=0.07$, $p=0.220$. The correlations from these analyses were practically zero. When the sample was split by sex, non-significant effects persisted. For males, these same relations were non-significant using either the total number of reported prosocial video games played, $r_{\mathrm{s}}=0.08, p=0.271$, or the composite prosocial video game variable, $r_{\mathrm{s}}=-0.03, p=0.419$. Amongst female participants, non-significant relations were found using either the total number, $r_{\mathrm{s}}=0.08, p=0.266$, or intensity of prosocial video game play, $r_{\mathrm{s}}=0.16, p=0.099$. All in all, no relations were found between prosocial video game exposure and sympathy scores on the empathy story stem. From these analyses, no support for the fifth hypothesis was seen.

\section{Relation between prosocial video game playing and the empathic concern scale of}

the IRI. The other measure of empathy that was used to test the fifth hypothesis was the empathic concern subscale of IRI. Parametric correlations (i.e., Pearson's) were calculated to delineate the link between prosocial video game play and scores on the empathic concern subscale. As a whole sample, no significant associations were found using either the total number of prosocial video games that participants reported to have played, $r=-0.05, p=0.265$, or the composite prosocial video game variable, $r=-0.10, p=0.130$. When the data were split by sex, the link between prosocial video game exposure and empathic concern scores remained nonsignificant. For males, no significant link was found using either the total number, $r=-0.04, p=$ 0.369 , or intensity of prosocial video game play, $r=-0.05, p=0.345$. Similarly, non-significant results were observed throughout the female participants in terms of the total number of 
prosocial video games that they reported playing, $r=0.09, p=0.238$, and the intensity of prosocial video game play, $r=0.11, p=0.182$. Thus, no support for the fifth hypothesis was found using empathic concern subscale scores.

\section{Hypothesis 6: Relation between Aggressive Driving Video Game Play and Prison Sentence}

The questionnaire included a question in which participants were asked to assume the role of judge in a hypothetical scenario involving a defendant stealing a car, eluding police during a chase, and hitting a pedestrian; participants were asked to assign the defendant a prison sentence, which varied in severity (see Table 7 on the following page). Spearman's correlations were run between prison sentence rating and both the number/intensity of aggressive driving video games participants reported playing, in terms of the whole sample and according to participant sex. This section aims to test the sixth hypothesis, which stated that participants who reported playing more aggressive driving video games would either a) demonstrate a more lenient attitude towards a convicted driver (i.e., give a less severe sentence in the prison sentence scenario) or b) display a more punitive attitude towards a convicted driver (i.e., give a more severe sentence in this same scenario).

Unlike the other hypotheses, two-tailed significance testing was used to evaluate this particular hypothesis, as it was unclear in which direction (i.e., to increase severity of sentence or to reduce it) the effect of video game playing might operate. In terms of aggressive driving video game play, as a whole group, the association was significant in terms of total number played, $r_{\mathrm{s}}=$ $-0.21, p=0.013$, but not intensity, $r_{\mathrm{s}}=-0.08, p=0.366$. In terms of total number of aggressive driving video games played, then, as participants' play more of these particular games, their prison sentence ratings decrease (i.e., become harsher). When the data were split by sex, this very association (using total number of aggressive driving video games played) persisted only for males, $r_{\mathrm{s}}=-0.28, p=0.022$, but not females, $r_{\mathrm{s}}=0.02, p=0.906$, which suggests that males' 
scores are the primary impetus for the significant correlation amongst the whole sample. As to the intensity of aggressive driving video game play, non-significant associations were found amongst males, $r_{\mathrm{s}}=-0.08, p=0.528$, and females, $r_{\mathrm{s}}=0.15, p=0.219$. Thus, the second version of the sixth hypothesis was supported; as a whole sample, participants who reported playing more aggressive driving video games (number but not intensity) gave harsher sentencing in the prison sentence scenario, but this effect seemed to apply only amongst males.

Table 7. Proportion of Participants Assigning a Prison Sentence in the Hypothetical Scenario Involving a Defendant Stealing a Car, Eluding Police, and Hitting a Pedestrian.

\begin{tabular}{lll}
\hline Prison Sentence* & Number of Male & Number of Female \\
& Participants $(n=66)$ & Participants $(n=69)$ \\
\hline (1) A 2-year prison sentence & 30 & 21 \\
(2) A 2-year driving ban \& 6-month prison sentence & 34 & 39 \\
(3) A 2-year driving ban & 1 & 6 \\
(4) A 6-month driving ban & 0 & 3 \\
(5) Probation & 1 & 0 \\
\hline
\end{tabular}

*The sentences are numerically listed in ascending order, from most to least severe. Note: Data for one of the male participants was missing and was thus not included in analysis.

Video Game Effects among Lighter Users

Amongst the entire sample of participants, seven participants had indicated that they played video games with some regularity weekly (i.e., between 20 and 30 hours; "heavy users"). To determine whether the correlations remained significant even after removing these cases from analyses, separate whole sample analyses were conducted for all of the hypotheses. It was found that even amongst "lighter" video game users (i.e., participants who reported playing video games less than 20 hours per week), all of the whole sample correlations remained significant (all $p \mathrm{~s}<0.05$ ), except for the relation between intensity of violent video game play and lower scores on the empathic concern subscale (Hypothesis 4; $p=0.317$ ). Thus, potential extreme cases did not really exert an undue influence on the whole-sample analyses in the present study. In terms of the analyses split according to participant sex, while the effects seemed to persist even after removing the heavy users, two marginally significant effects emerged. For males, the 
relation between the intensity of aggressive driving video game play and scores on the third story stem was marginally significant (Hypothesis $2 ; p=0.075$ ), as was the relation between intensity of violent video game play and attribution style on the third story stem (Hypothesis $3 ; p=0.052$ ). Altogether, the results from the present thesis suggest that video game effects may even be present amongst lighter users, even when ignoring the playing habits of heavy players.

\section{Summary of Results}

For convenience, Table 8 below illustrates the significant and non-significant results that emerged from the present study.

Table 8. Summary of the Statistically Significant \& Non-Significant Results for Each Hypothesis.

\begin{tabular}{|c|c|c|c|c|}
\hline Hypothesis & Specific Effect Tested & $\begin{array}{l}\text { Results for Whole } \\
\text { Sample }\end{array}$ & $\begin{array}{l}\text { Results for Male } \\
\text { Participants Only }\end{array}$ & $\begin{array}{l}\text { Results for Female } \\
\text { Participants Only }\end{array}$ \\
\hline \multirow[t]{4}{*}{$\begin{array}{l}\text { (1) VVGs increase } \\
\text { aggression }\end{array}$} & $\begin{array}{l}\text { Total VVGs played on SS1 } \\
\text { written responses }\end{array}$ & Significant & Non-significant & Non-significant \\
\hline & $\begin{array}{l}\text { Intensity of VVGs on SS1 } \\
\text { written responses }\end{array}$ & Significant & Non-significant & Non-significant \\
\hline & $\begin{array}{l}\text { Total VVGs played on SS2 } \\
\text { written responses }\end{array}$ & Non-significant & Non-significant & Non-significant \\
\hline & $\begin{array}{l}\text { Intensity of VVGs played on } \\
\text { SS2 written responses }\end{array}$ & Non-significant & Non-significant & Non-significant \\
\hline \multirow{4}{*}{$\begin{array}{l}\text { (2) VVGs/ADVGs } \\
\text { increase aggressive } \\
\text { driving }\end{array}$} & $\begin{array}{l}\text { Total VVGs played on SS3 } \\
\text { written responses }\end{array}$ & Significant & Significant & Non-significant \\
\hline & $\begin{array}{l}\text { Intensity of VVGs played on } \\
\text { SS3 written responses }\end{array}$ & Significant & Significant & Non-significant \\
\hline & $\begin{array}{l}\text { Total ADVGs played on SS3 } \\
\text { written responses }\end{array}$ & Significant & Non-significant & Non-significant \\
\hline & $\begin{array}{l}\text { Intensity of ADVGs played } \\
\text { on SS3 written responses }\end{array}$ & Significant & Significant & Non-significant \\
\hline \multirow[t]{4}{*}{$\begin{array}{l}\text { (3) VVGs increase } \\
\text { HAB }\end{array}$} & $\begin{array}{l}\text { Total VVGs played on HAB } \\
\text { ques. for SS3 }\end{array}$ & Non-significant & Non-significant & Significant \\
\hline & $\begin{array}{l}\text { Intensity of VVGs played on } \\
\text { HAB ques. for SS3 }\end{array}$ & Non-significant & $\begin{array}{l}\text { Significant (but } \\
\text { opposite to } \\
\text { prediction) }\end{array}$ & Non-significant \\
\hline & $\begin{array}{l}\text { Total ADVGs played on } \\
\text { HAB ques. for SS3 }\end{array}$ & Significant & Non-significant & Non-significant \\
\hline & $\begin{array}{l}\text { Intensity of ADVGs on } \mathrm{HAB} \\
\text { ques. for SS3 }\end{array}$ & Non-significant & Non-significant & Non-significant \\
\hline $\begin{array}{l}\text { (4) VVGs decrease } \\
\text { empathy }\end{array}$ & $\begin{array}{l}\text { Total VVGs played on SS4 } \\
\text { written responses (Unsymp.) }\end{array}$ & Non-significant & Non-significant & Non-significant \\
\hline
\end{tabular}




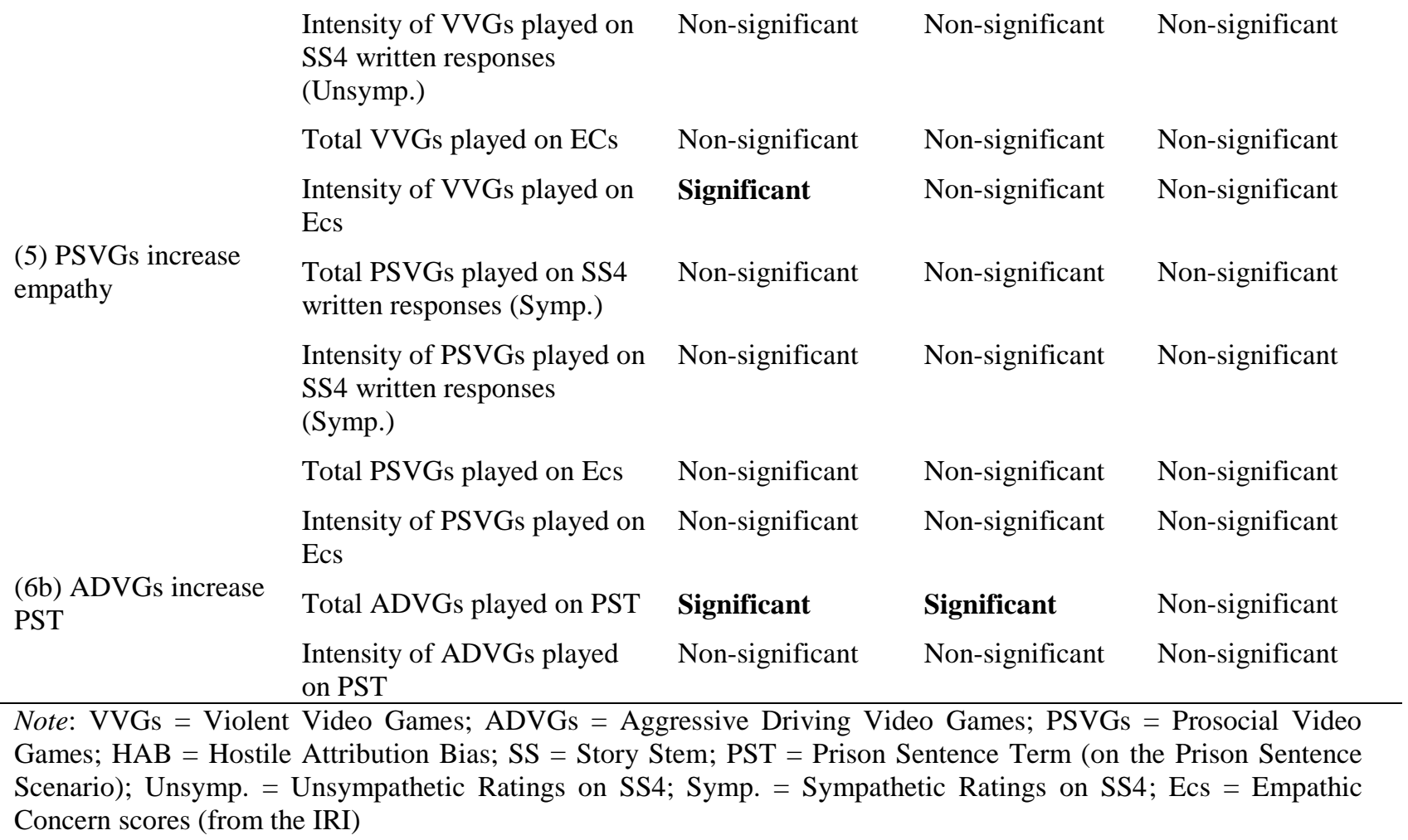




\section{Discussion}

The present study aimed to illuminate the effects of playing violent and prosocial video game genres on participants' aggression (i.e., physical and relational aggression), attribution styles (i.e., benign or hostile), aggressive driving tendencies (i.e., reactivity to a hypothetical driving scenario in which one's parking spot is stolen), and empathy (i.e., reactivity to a hypothetical scenario in which one witnesses another person trip and fall, and empathic concern).

\section{General Findings}

Is Video Game Play Related to Increased Aggression? Hypotheses 1 and 2 tested versions of the claim that playing video games increased aspects of aggression. When examining the whole sample of participants, there were significant positive correlations between violent and aggressive driving video game use and aggressive responses to a story stem tapping physical aggression (Story Stem One) and aggressive driving (Story Stem Three), but not relational aggression (Story Stem Two). However, because these whole sample analyses included both male and female participants, participant sex is a potential confound in these analyses. In other words, these whole sample analyses may just demonstrate that males, who happen to play more video games than females, also happen to give more aggressive responses than females, without there necessarily being a direct connection between video game play and aggression. So, these analyses offer only weak support to the first and second hypotheses.

When the same analyses were conducted separately for male and female participants, the only relations that retained statistical significance were the positive correlations between playing violent or aggressive driving video games and male participants' aggressive responses to the driving scenario (Story Stem Three). Thus, only the link between males' violent and aggressive driving video game playing and aggression in response to a driving scenario received the strongest (i.e., unconfounded) support in the present study. 
Is Video Game Play Related to Increased Hostile Attribution Bias? Here, three of four whole sample analyses of the relations between violent or aggressive driving video game play and hostile attribution bias (in Story Stem Three) were non-significant; only the total number of aggressive driving video games played was positively correlated with participants' hostile attribution bias. Of the same analyses conducted separately for males and females (and thus unconfounded by participant sex), only two of eight analyses were statistically significant. The total number of violent video games played was positively correlated with hostile attributions for female participants. However, the intensity of violent video game playing (total number $\mathrm{x}$ hours played per week) was negatively correlated with male participants' hostile attributions. Thus, in terms of the third hypothesis, there was no consistently strong evidence for a relation between video game play and increased hostile attribution bias in the present study.

Is Video Game Play Related to Empathy? For hypotheses 4 (violent video games decrease empathy) and 5 (prosocial video games increase empathy), only one of eight whole sample analyses revealed a significant correlation between video game use and empathy. In particular, a significant negative correlation between the intensity of violent video game use and the empathic concern subscale of the IRI was found. None of the analyses performed separately for male and female participants revealed a statistically significant relation. Thus, no strong evidence for links between violent video game use and empathy was found in the present study.

\section{Is Video Game Play Related to Judgements of the Severity of a Driving-Related}

Offence? For the final hypothesis, there was a statistically significant correlation between the total number of aggressive driving video games played (but not the intensity of aggressive driving video game play) and the severity of judgements for the driving-related offence, both in the whole sample and among the male (but not the female) participants. Among the male 
participants, there was thus some strong support for an association between aggressive driving video game play and giving more severe sentences in a hypothetical case of aggressive driving.

\section{The Present Results: Comparison with Previous Literature and Implications}

The results from the present study, which generally found weak evidence for the effects of video games on users, are at odds with most of the previous literature on video games. The findings from the present study have a number of important implications that video game users may not necessarily realize. However, since the study is primarily correlational and found only limited effects, these implications are speculative at best. The link between violent video game exposure and increased physical aggression scores (as measured in the present study by written

responses to story stems) may suggest that repeated use of these games have the potential to shape users to become generally more aggressive on a psychological level. This finding corroborates research by Krahé and Möller (2004), who found that students (especially males) who liked more violent video games perceived physical aggression as an appropriate and normal response to a potential threat cue. If this association is in fact real, then certain video game users, such as individuals who play copious amounts of violent video games, should perhaps moderate their playing.

Additionally, the relation between aggressive driving video games and more aggressive responses on the driving story stem might indicate that young adolescents should abstain from heavy use of these games, as repeated exposure could potentially help to foster some of the very behaviours of aggressive driving, such as speeding. The effects regarding aggressive driving video games found in the present study, though weak, are congruent with the findings of Bushman and Anderson (2002), who reported that participants who played a violent, relative to a nonviolent, video game scored higher on aggressive thoughts, feelings, and actions to a hypothetical story stem scenario involving a car being rear-ended. In addition, Transport Canada 
(2011) reports that " $40 \%$ of speeding drivers involved in fatal crashes were 16 to 24 years of age" (p. 12); the mean age of the participants for the present sample (i.e., 20.66 years) falls precisely in the middle of this age range of speeding drivers involved in crashes in Canada. Thus, individuals between the ages of 16 and 24 (i.e., adolescents and young adults) might be especially prone to the influence of aggressive driving video games.

The finding that participants who made a hostile attribution, in comparison to a benign one, reported playing more aggressive driving video games might suggest that these very games shape a hostile attributional style in users to potentially threatening situations, or it may simply suggest that users with a hostile attributional style like more of these games. However, as an opposite pattern was found between increased violent video game play and benign attributions (instead of hostile ones) amongst males, the present study does not provide compelling evidence that playing violent video games increases hostile attribution bias. Furthermore, the weak relation between hostile attribution bias and violent video game play that was found in the present thesis may suggest that a third factor, such as perceived norms of aggression as an appropriate response to interpersonal conflict, may moderate this connection (as Krahé \& Möller, 2004, found). Kirsh (1998), who found that violent video game play was linked with hostile attribution bias, only found effects on three of the six interpersonal aggression story stems, which perhaps further highlights that the link between violent video games and hostile attribution bias is unclear.

The significant link that was found between the intensity of violent video game play and reduced empathy lends some support to the literature which documents the desensitizing effects of violent media (e.g., Bushman \& Anderson, 2009). However, given that this was the only significant link that was found out of the twelve tests that were conducted for the fifth hypothesis, the present study does not strongly support this connection. Furthermore, the link 
between playing more aggressive driving video games and harsher prison sentence attitudes perhaps reinforces the literature on violent media fostering schadenfreude in users.

The lack of effects found amongst prosocial video game use in the present study is inconsistent with the literature. Participants in the present study reported playing few, if any, prosocial video games, which might help to explain the non-significant findings for the fifth hypothesis. In addition, while classifying all of the video games that were collected for analysis, it became apparent that there are few video games on the market that are genuinely prosocial to begin with. One might argue that a genuinely prosocial video game is one in which the plot is altruistic in nature, but game play does not involve or display on-screen any aggressive moves or violence. Such games were certainly rare. Thus, the lack of prosocial video game play amongst participants may also account for the lack of significant effects.

Taken together, while no definitive evidence was found, results from the present study suggest that since video games may influence users on a number of dimensions, players should be mindful of the detrimental effects that repeated use can have on the user.

\section{Notes on Statistical Power and Statistical Analyses in the Present Study}

Two comments on the overall lack of strong evidence for the influence of video games on aggression, hostile attribution bias, and empathy in the present study deserve mention. First, given the larger sample size, the analyses of the whole sample had more statistical power than the analyses split by participant sex. However, as previously noted, analyses based on the entire sample were evidently confounded by participant sex, so the analyses were run separately for males and females. According to GPower analyses (which is a popular software tool for conducting power analyses), the sample sizes of 67 males and 69 females had an acceptable power of 0.8 (i.e., an 80 percent chance of detecting an effect) for finding correlations of $r=0.30$

for males and $r=0.29$ for females. Thus, the present study had an acceptable power in the 
analyses split by participant sex to find medium-sized correlations between video game use and the aggressive or empathic outcomes. However, prior meta-analyses seem to indicate that the effect of violent video games on aggressive cognition or affect is between $r=0.18$ (from Anderson et al., 2010) and $r=0.27$ (from Bushman \& Anderson, 2001). To that extent, the comparisons split by participant sex in the present study may have been underpowered to find effects. Thus, one possibility is that the effects of video games on aggression and empathy are true effects, but that a lack of power in the analyses split by sex may have contributed to the lack of significant effects that were found overall.

Another point which merits commentary concerns the flexibility that was found when analyzing the results from this study. There were several measures of violent and prosocial video games that a researcher could elect to use for analysis, including the total number of games played, the number of hours per week playing video games, the intensity of game play (total number $\mathrm{x}$ hours played per week), participants' listed favourite video games, and so on. Similarly, for some of the predicted variables (e.g., aggression), there were several measures that could have been used (e.g., the participant's responses to Story Stem One, Story Stem Two, Story Stem Three, or some kind of composite of all three responses). Freedman (2002) has suggested that this very flexibility in the measures one might use to assess the relation between media use and aggression is one factor that leads to false positives in the literature. In other words, researchers may assess the relations between many different measures of violent media use and many different measures of aggression, then present only those results that achieve statistical significance. Perhaps, then, previous work on the links between media use and aggression is not as strong as it may appear. To the present thesis's credit, only a few selected measures which made the most sense to use, such as the total number of games played and intensity of game play, were consistently applied while testing each of the hypotheses. 


\section{Strengths and Limitations}

The present study has many strengths and weaknesses. In terms of its strengths, this study used a medley of both quantitative and qualitative measures. Indeed, the standardized measures that were used in this study (i.e., the PANAS, IRI, NEO-FFI-3, and PBI) are well validated in the literature. Furthermore, by electing to employ the story stem methodology, a rich set of data were collected that illuminates the typical responses to both aggressive and empathic hypothetical scenarios. Answers from the story stems encompassed a wide range of responses, which varied in terms of the degree of emotions felt (i.e., aggressive or sympathetic). However, an inevitable trade-off was encountered when using the story stem measures; while they permit researchers to collect a rich amount of data, codifying the responses for statistical analysis is not always a straightforward process. An additional strength of the present study is that an effort was made to assess the participant's mood (i.e., using the PANAS) prior to their participation in the study. This was important in that it allowed an assessment of whether aggressive responses to the story stems were driven primarily by participants' transient mood states, as compared to their enduring trait levels of aggression. Also, a further strength of the present study was that efforts were made to include an equal sex split.

While the present study contains several strengths, it also has some limitations.

One limitation is that the results are entirely correlational in nature, as participants were asked to self-report on the questionnaire. Correlational findings do not necessarily translate into factual, cause-and-effect statements, as there is always the issue of a tertium quid (i.e., a third variable) or the direction of causality (Field, 2009). For example, the present study's finding that participants as a whole sample who reported playing more violent/aggressive driving video games (total number and overall intensity) scored higher on aggression ratings on the driving scenario might be better accounted for by an extraneous variable, such as participants' 
personality factors. As Harris and Houston (2010) mention, there are several psychological factors that are associated with aggressive driving (and, by extension, affinity towards aggressive driving video games), which include sensation seeking, trait hostility, and a high competitive drive. Furthermore, it is difficult to state, with any certainty, whether participants with a hostile attribution bias like more aggressive driving video games or whether participants who play more of these games are more likely to display a hostile attribution bias. Like in this study, the direction of causality is difficult to ascertain from correlational findings.

Another limitation is that the male participants scored significantly higher on both agreeableness (as measured by the NEO-FFI-3) and positive affect scores (as measured by the PANAS) relative to females. Thus, it is possible that the males' agreeableness and positive affect scores dampened their scores on the aggression measures used throughout the study. Indeed, it could well be the case that the present sample of males is generally non-aggressive. Additionally, as a convenience sample was used for the purpose of recruiting participants for the present study, the sample collected may not be the most representative sample for this study. Indeed, the sample was a university student body, where the expression of anger is certainly not a sanctioned behaviour. Furthermore, university students in general may not play video games as much as they used to in their earlier years, as they are oftentimes pressed for time due to scholarly work. A study examining the effects of violent video game play may find stronger results with a younger sample. Horse play, for example, oftentimes occurs in elementary and secondary schools, meaning that norms against aggressive conduct may not be as firmly established in a younger sample. Additionally, younger people are more likely to play a greater amount of video games than are college or university students.

While the story stem methodology was designed to be an effective way to disguise the study's fundamental focus on video games, some of them were perhaps not sensitive enough to 
detect the effects of interest. The relational aggression story stem in particular failed to capture potential feelings of indirect aggression amongst the participants. Indeed, most participants responded to this story stem by stating that they would not be bothered by not being invited to the party, would understand that their friendship with the other students is not at a level where party invitations would be expected, or would think that the students would invite them later. Maybe a more appropriate relational aggression scenario would have been one in which an ambiguous derogatory statement was the potential threat cue. However, when researching an area in which the potential for demand is high (such as when researching the links between video game use and aggression), measures must be created and selected with care. In devising story stem scenarios for the present study, an attempt was made to achieve a delicate balance in which the story stems were adequately measuring the real construct under study, yet were not too obvious in what they measured. Although the story stems used in the present study were all adapted from previous research, perhaps some were not sensitive enough to capture variation in feelings of aggression. Thus, the present study has both its strengths and limitations.

\section{Future Directions for Research on Video Game Effects}

Future research that investigates the effects of video game exposure would do well to bear the following points into consideration. While participants can free-report their answers when they are presented with ambiguous story stems, the codification of their answers into representative response categories is not always a straightforward feat, nor is it economical on a researcher's time. For example, it was hard to codify some of the participant's responses neatly into the categories that were selected for codification purposes, as some of the answers were contingent upon extraneous factors (such as the protagonist's sex and the respondent's time constraints in the given scenario). Thus, if researchers choose to use story completion tasks in video game research, it is advised that they use a forced-choice response style, as this would 
facilitate both data analysis and codification efforts. Researchers interested in the topic of video game effects could certainly use the response categories devised from this study, granted that they are interested in this medium's aggressive and empathic influences, as these categories are representative of how many participants would respond to these particular scenarios.

In consideration of the limitation stated earlier about using a convenience sample, future studies could elect to use an online recruitment approach to collecting their data, which would allow for an even bigger sample. Efforts might also be made to recruit more avid gamers in the sample. For example, a researcher might try to recruit participants for the study by posting a link to the study on forums devoted to discussing video games. However, the problem with using such a sample for video game research is that avid video game players may easily detect the study's true purpose. Thus, if an online sample was used, researchers would do well to use an online method of data collection, such as the Amazon Mechanical Turk (MTurk), where data can be gathered from a sample of people (including gamers) without specifically targeting gamers. At present, though, Canadian researchers cannot directly upload studies to MTurk.

Finally, perhaps a child or adolescent sample of participants would be most appropriate for research on video game effects, as younger individuals are more likely to play video games than are older people, and may be more susceptible to their effects. There are thus several possible avenues that video game researchers can explore in future studies on this topic. 


\section{Conclusion}

In closing, the present thesis contributes to the literature which investigates the link between video game exposure (i.e., violent, aggressive driving, and prosocial types) and four outcomes of social behaviour (i.e., aggression, attribution style, aggressive driving tendencies, and empathy). Results partially supported an effect for violent and aggressive driving video games, but not for prosocial video games. Researchers interested in the influence of video games on users might elect to use the story stem methodology in their studies to divert participants' attention away from the focus on video games. As video games are continuing to gain acceptance among a greater number of individuals over time, and are "transporting" users into more realistic on-screen milieus, research on this topic will continue to investigate its ability to transform players on a number of levels. 
Appendix A: Media Consumption Statistics for the Sample

Media Consumption Statistics for the Sample $(N=136)$.

Characteristic

Min

Max

$M$

$S D$

Number of Fictional Narratives Read

Overall

Males

0

4.76

5.86

Females

0

48

3.04

4.42

0

48

6.43

6.60

Number of Violent TV Programs Watched

Overall

$0 \quad 30$

10.57

5.18

Males

0

21

9.45

4.49

Females

2

30

11.65

5.59

Number of Prosocial TV Programs Watched

Overall

Males

0

0

Females

0

4

0.95

0.95

0.79

1.01

Number of Violent Video Games Played

Overall

Males

0

1.10

0.88

Females

0

7.05

6.79

0

34

10.10

7.22

4.09

4.78

Number of Prosocial Video Games Played

Overall

Males

$\begin{array}{ll}0 & 17\end{array}$

1.84

2.58

0

17

2.31

3.22

Females

0

7

1.38

1.64

Number of Risky Driving Video Games

Played

Overall

$0 \quad 12$

2.77

2.67

$0 \quad 12$

Males

0

12

4.30

2.66

Females

Hours Per Week Reading

Overall

$0 \quad 70$

1.29

1.66

Males

$0 \quad 50$

9.64

11.33

$1 \quad 70$

8.30

10.66

10.95

11.87

Females

Hours Per Week Watching TV

Overall

$0 \quad 40$

9.36

8.26

$0 \quad 40$

9.09

7.95

Males

0

40

9.63

8.61

Females

Hours of Video Game Play Per Week

Overall

$0 \quad 30$

4.29

6.44

$0 \quad 30$

Males

0

20

6.80

7.85

Females

1.82

3.15

Note $:$ Min $=$ minimum value Max $=$ maximum value $; M=$ mean $; S D=$ standard deviation . 
Rating the video games in terms of their violent content was not always an easy task, as the content of video games varies by, for example, platform and version. Video games were rated as violent if they received a rating of $T$ (Teen), $M$ (Mature), or $A$ (Adults Only) by the Entertainment Software Rating Board (ESRB). If no rating was available, other sources were secured (e.g., www.gamefaqs.com). In addition, video games were rated as nonviolent if they received a rating of $e C$ (Early Childhood), $E$ (Everyone), or E10+ (Everyone 10+) by the ESRB. The nonviolent video games were further screened to see if any of these games contained altruistic or prosocial themes (i.e., could be classified as "prosocial" video games). For example, Lemmings is rated as $E$ by the ESRB, regardless of version, and successful game play commands altruistic navigation (i.e., leading the lemmings to the exit). Furthermore, with respect to the violent video games, these games were screened for aggressive driving content (i.e., if they involved racing or operating a weaponized vehicle; these were classified as "aggressive driving video games"). For example, Crazy Taxi is rated as E, E10+, and T, depending on version or platform. While the ESRB categorization does not fit nicely with the violent/nonviolent video game distinction, further research into this video game (as well as any others that were listed by the participants that contained multiple ESRB ratings) revealed that the player can commit acts of aggressive driving, such as speeding and hitting other cars (although, to its credit, this game generally does not condone such driving practices).

While not directly relevant to the present thesis, the TV programs were rated as nonviolent if they were classified as $C$ (Children), $C 8$ (Children $8+$ ), or $G$ (General Audience) by the International Movie Database (IMDb). Of the nonviolent TV programs, any with prosocial plots were classified as "prosocial" TV programs (e.g., Touched by An Angel). TV programs were rated as violent if they received a rating of $P G$ (Parental Guidance), 14+ (Ages 14+), or $18+($ Ages $18+$ ) by the IMDb. If no ratings were found using the IMDb, other sources were used, such as www.tvguide.com or www.amazon.com.

The books that participants listed reading were categorized as fiction or nonfiction. For example, if participants listed the names of textbooks, newspapers, or biographical books, then these compositions were rated as non-fiction (e.g., Gender in Canada). Any books that were classified as fantasy, drama, science fiction, or romance were classified as fictional pieces (e.g., Harry Potter series). In most cases, the genre of books was verified using primarily www.waterstones.com, but sometimes www.amazon.com, or other sources, if needed. 
Appendix B: Demographic, Media Consumption, and Story Stem Questions

\section{Demographic Questionnaire}

1. Please indicate your gender:

Male

Female

2. Do you have a driver's license?

Yes No

3. Please indicate your age:

4. How many days per month do you drive?

5. What is your current university major?

6. Please list the names of any video games you have played within the last year? List as many as you can remember, regardless of platform.

7. Which video games would you consider to be your favourite? (List up to four of them.)

8. Approximately how many hours per week do you spend playing video games?

9. Please list the names of any books you have read within the last year. List as many as you can remember, regardless of genre.

10. Which books would you consider to be your favourite? (List up to four of them.)

11. Approximately how many hours per week do you spend reading?

12. Please list the names of any television programs you have watched on a regular basis within the last year. List as many as you can remember, regardless of genre.

13. Which television programs would you consider to be your favourite? (List up to four of them.)

14. Approximately how many hours per week do you spend watching television?

15. Please indicate whether or not you have watched any of the following television shows.

\begin{tabular}{|l|l|l|}
\hline TV SHOW & Watched It & $\begin{array}{c}\text { Haven't } \\
\text { Watched It }\end{array}$ \\
\hline Big Bang Theory & & \\
\hline Grey's Anatomy & & \\
\hline Full House & & \\
\hline Glee & & \\
\hline How I Met Your Mother & & \\
\hline The Simpsons & & \\
\hline Dr. Oz Show & & \\
\hline
\end{tabular}




\begin{tabular}{|l|l|l|}
\hline Family Guy & & \\
\hline Cops & & \\
\hline Chase & & \\
\hline Criminal Minds & & \\
\hline Bones & & \\
\hline X Factor & & \\
\hline CSI: Miami & & \\
\hline
\end{tabular}

16. Please indicate whether you have heard of or played any of the following videogames (check either heard of it if you have only heard of the videogame, and check played it if you have actually played the respective videogame). If you haven't heard of or played the videogame, then leave the respective row blank:

\begin{tabular}{|l|l|l|l|}
\hline VIDEO GAME & Heard Of It & Played It & Neither \\
\hline Call of Duty: Modern Warfare 3 $(A)$ & & & \\
\hline Just Dance 3 $(N)$ & & & \\
\hline Elder Scrolls V: Skyrim $(A)$ & & & \\
\hline Battlefield 3 $(A)$ & & & \\
\hline Madden NFL 12 $(N)$ & & & \\
\hline Call of Duty: Black Ops $(A)$ & & & \\
\hline Batman: Arkham City $(A)$ & & & \\
\hline Gears of War 3 $(A)$ & & & \\
\hline Just Dance 2 $(N)$ & & & \\
\hline Assassin's Creed: Revelations $(A)$ & & & \\
\hline Kingdoms of Amalur: Reckoning $(A)$ & & & \\
\hline UFC Undisputed 3 $(A)$ & & & \\
\hline Skylanders: Spyro's Adventure $(E)$ & & & \\
\hline Resident Evil: Operation Raccoon City $(A)$ & & & \\
\hline NBA 2K12 $(N)$ & & & \\
\hline Mass Effect 3 $(A)$ & & & \\
\hline
\end{tabular}

*Note: $A$ represents an aggressive video game; $E$ represents a prosocial game; $N$ indicates a neutral game.

17. Please indicate whether you have heard of or played any of the following videogames (check either heard of it if you have only heard of the videogame, and check played it if you have actually played the respective videogame). If you haven't heard of or played the videogame, then leave the respective row blank:

\begin{tabular}{|l|l|l|l|}
\hline VIDEO GAME & Heard Of It & Played It & Neither \\
\hline Carnival Games $(N)$ & & & \\
\hline Excite Truck $(N)$ & & & \\
\hline Mirror's Edge $(A)$ & & & \\
\hline Dirt 2 $(N)$ & & & \\
\hline Prince of Persia $(E)$ & & & \\
\hline Chevrolet Camaro: Wild Ride $(N)$ & & & \\
\hline Ghostbusters: The Video Game $(N)$ & & & \\
\hline Grand Theft Auto (any of series) $(A D)$ & & & \\
\hline
\end{tabular}




\begin{tabular}{|l|l|l|l|}
\hline Chrysler Classic Racing $(N)$ & & & \\
\hline Mortal Kombat: Deception $(A)$ & & & \\
\hline London Taxi Rush $(N)$ & & & \\
\hline Cars 2 $(N)$ & & & \\
\hline Speed Racer Video Game $(N)$ & & & \\
\hline Monster 4 x 4: Stunt Racer $(N)$ & & & \\
\hline Wii Sports $(N)$ & & & \\
\hline The Sims $(A)$ & & & \\
\hline Minecraft $(N)$ & & & \\
\hline Portal $(A)$ & & & \\
\hline Crazy Taxi $(A D)$ & & & \\
\hline Journey $(E)$ & & & \\
\hline Dance on Broadway $(N)$ & & & \\
\hline Burnout (any of series) $(A D)$ & & & \\
\hline Chibi Robo $(N)$ & & & \\
\hline Need for Speed (any of series) $(A D)$ & & & \\
\hline Super Mario Sunshine $(E)$ & & & \\
\hline Midnight Club (any of series) $(A D)$ & & & \\
\hline Lemmings $(E)$ & & & \\
\hline Project Gotham Racing (any of series) $(N)$ & & & \\
\hline Zoo Vet $(E)$ & & & \\
\hline Ridge Racer (any of series) $(A D)$ & & & \\
\hline Animal Crossing $(E)$ & & & \\
\hline Test Drive Unlimited 1 or 2 $(A D)$ & & & \\
\hline Blur $(N)$ & & & \\
\hline Motorstorm (any of series) $(A D)$ & & & \\
\hline
\end{tabular}

*Note: $A$ represents an aggressive video game; $A D$ denotes an aggressive driving video game; $E$ represents a prosocial game; $N$ indicates a neutral game.

\section{Story Stem Vignettes and Questions}

\section{General Aggression Stems}

\section{Physical Aggression Stem}

- Imagine that you're walking outside on campus while wearing your new shoes that you have just recently purchased. You really like your new shoes and it's the first day that you've worn them. Suddenly, you are bumped from behind by another student from your class on the sidewalk. You stumble into a puddle and your new shoes get muddy.

1. Describe six things you would do, say, think, or feel in this situation.

2. What do you think is the most likely explanation for why this person bumped into you?

a. They were clumsy and bumped into you by accident.

b. They were careless and weren't looking where they were going.

c. They were mean and bumped into you on purpose. 
Relational Aggression Stem

- Imagine that you are in the washroom one day after class. While you are in there, two other students come in and start talking to each other. You met these students in class this semester and have recently started to think that you might be becoming friends. While in the washroom, you hear one of them invite the other one to a party. The student says that there are going to be a lot of people at the party. You have not been invited to this party.

1. Describe six things you would do, say, think, or feel in this situation.

2. What do you think is the most likely explanation for you not being invited to the party?

a. The student simply forgot that you haven't been invited. When they realize this, they will invite you later.

b. The student was being thoughtless. They didn't consider your feelings in inviting someone else to the party in front of you.

c. The student was being mean. They deliberately invited someone else to the party in front of you, to hurt your feelings.

\section{Driver Aggression Stem}

- Imagine you are in a full parking lot. You see a driver leaving and you put on your blinker to indicate that you intend to take the parking space. As the other driver pulls out, a second driver cuts in front of you from the other side and takes the parking space.

1. Describe six things you would do, say, think, or feel in this situation.

2. What do you think is the most likely explanation for the other driver taking your parking spot?

a. The driver didn't notice that you were waiting to park in that spot.

b. The driver was being thoughtless and didn't think that taking the parking spot would be a big deal.

c. The driver was being rude and deliberately took your spot, knowing how annoyed it would make you.

\section{Empathy Stem}

- Imagine you are walking along a sidewalk on a cold winter day. Some distance ahead, you can see a man crossing the street while texting on his phone. A few seconds later, as he gets to the other side of the street, he trips on the curb of the sidewalk and falls down, dropping his phone. There isn't really anyone else around and you are not too far from the man.

1. Describe six things you would do, say, think, or feel in this situation.

2. How do you think you would most likely feel in this situation?

a. Mostly sympathy for the fallen man. It's not nice to fall on the ground.

b. A mix of emotions. Some sympathy for the man, but also some satisfaction that he fell down. 
c. Mostly just pleased or amused that the man fell down.

d. No particular emotion.

\section{Additional Dependent Variable (Value Judgement, Prison Sentence)}

- You are the judge in a case in which the jury has convicted the defendant of aggressive driving and injuring a pedestrian. The defendant stole a car, failed to stop for the police while being chased, and drove on a sidewalk and hit a pedestrian, who then suffered from a broken leg. Assuming you have the authority to give any of the following sentences, which sentence would you give to the defendant in this case?
(a) A 2-year prison sentence.
(c) A 2-year driving ban.
(d) A 6-month driving ban.
(e) Probation.

(b) A 2-year driving ban and a 6-month prison sentence.

[Adapted from Barlett, Harris, \& Baldassaro (2007)] 
Appendix C: Statistics for the Standardized Measures Used in the Present Study Statistics for the Standardized Measures Used in the Present Study.

\begin{tabular}{|c|c|c|c|c|}
\hline Measure & Min & $\operatorname{Max}$ & $M$ & $S D$ \\
\hline \multicolumn{5}{|l|}{ PANAS } \\
\hline \multicolumn{5}{|c|}{ Positive Affect Score } \\
\hline Overall & 12 & 50 & 29.11 & 8.08 \\
\hline Males & 12 & 50 & 30.76 & 8.14 \\
\hline Females & 13 & 45 & 27.51 & 7.74 \\
\hline \multicolumn{5}{|c|}{ Negative Affect Score } \\
\hline Overall & 10 & 50 & 15.61 & 5.69 \\
\hline Males & 10 & 50 & 15.97 & 6.08 \\
\hline Females & 10 & 32 & 15.26 & 5.30 \\
\hline \multicolumn{5}{|l|}{ NEO-FFI-3 } \\
\hline \multicolumn{5}{|c|}{ Openness to Experience } \\
\hline Overall & 18 & 36 & 26.26 & 3.49 \\
\hline Males & 18 & 36 & 26.66 & 4.05 \\
\hline Females & 20 & 31 & 25.88 & 2.83 \\
\hline \multicolumn{5}{|c|}{ Conscientiousness } \\
\hline Overall & 22 & 39 & 29.74 & 3.34 \\
\hline Males & 22 & 39 & 30.03 & 3.34 \\
\hline Females & 22 & 38 & 29.45 & 3.33 \\
\hline \multicolumn{5}{|c|}{ Extraversion } \\
\hline Overall & 18 & 38 & 27.29 & 3.63 \\
\hline Males & 20 & 38 & 27.55 & 3.69 \\
\hline Females & 18 & 35 & 27.04 & 3.58 \\
\hline \multicolumn{5}{|c|}{ Agreeableness } \\
\hline Overall & 11 & 35 & 22.91 & 4.48 \\
\hline Males & 16 & 35 & 24.39 & 4.39 \\
\hline Females & 11 & 33 & 21.48 & 4.11 \\
\hline \multicolumn{5}{|l|}{ Neuroticism } \\
\hline Overall & 9 & 35 & 22.67 & 4.97 \\
\hline Males & 12 & 35 & 22.21 & 4.87 \\
\hline Females & 9 & 33 & 23.12 & 5.06 \\
\hline \multicolumn{5}{|l|}{ IRI } \\
\hline \multicolumn{5}{|c|}{ Empathic Concern } \\
\hline Overall & 7 & 28 & 20.73 & 4.51 \\
\hline Males & 7 & 28 & 19.46 & 4.82 \\
\hline Females & 13 & 28 & 21.96 & 3.83 \\
\hline \multicolumn{5}{|c|}{ Fantasy Scale } \\
\hline Overall & 3 & 28 & 18.71 & 6.20 \\
\hline Males & 3 & 28 & 17.76 & 6.00 \\
\hline Females & 4 & 28 & 19.64 & 6.29 \\
\hline Perspective & & & & \\
\hline
\end{tabular}




\begin{tabular}{|c|c|c|c|c|}
\hline Overall & 3 & 28 & 17.91 & 4.98 \\
\hline Males & 3 & 27 & 17.52 & 5.04 \\
\hline Females & 6 & 28 & 18.29 & 4.92 \\
\hline \multicolumn{5}{|c|}{ Personal Distress } \\
\hline Overall & 1 & 23 & 12.19 & 4.39 \\
\hline Males & 3 & 23 & 11.43 & 4.39 \\
\hline Females & 1 & 21 & 12.93 & 4.29 \\
\hline \multicolumn{5}{|l|}{ PBI } \\
\hline \multicolumn{5}{|l|}{ Care Score } \\
\hline Overall & 9 & 35 & 27.50 & 5.84 \\
\hline Males & 9 & 34 & 27.55 & 5.66 \\
\hline Females & 11 & 35 & 27.45 & 6.06 \\
\hline \multicolumn{5}{|c|}{ Overprotection Score } \\
\hline Overall & 0 & 36 & 14.59 & 6.98 \\
\hline Males & 0 & 34 & 14.60 & 6.44 \\
\hline Females & 1 & 36 & 14.58 & 7.52 \\
\hline
\end{tabular}

Note $:$ Min = minimum value Max = maximum value,$M=$ mean; $S D=$ standard deviation. 
Appendix D: Subsidiary Hypotheses (Fictional Narratives and Parenting Style)

\section{Hypothesis S1: Relation between Participants' Responses to Story Stem Four (Empathy}

\section{Scenario, Sympathy), Their Empathic Concern Scores, and their Reading Habits}

This section endeavours to address the first subsidiary hypothesis, which stated that participants who reported reading more fictional narratives would score higher on empathy.

\section{Relation between the number of fictional narratives read and written responses to} story stem four (Sympathy Ratings). One test of the first subsidiary hypothesis involved computing non-parametric correlations (i.e., Spearman's) between sympathy ratings on the empathy stem and the total number of fictional narratives that participants reported to have read. As a whole sample, no significant association was found, $r_{\mathrm{s}}=0.05, p=0.300$. The magnitude of this correlation was practically zero. When the sample was split by sex, this same relation remained non-significant for males, $r_{\mathrm{s}}=0.06, p=0.318$, as well as females, $r_{\mathrm{s}}=0.15, p=0.104$. In short, no support for the fifth hypothesis was observed based on these findings.

\section{Relation between the number of fictional narratives read and scores on the} empathic concern scale of the IRI. Another test of the first subsidiary hypothesis was conducted by running a parametric correlation (i.e., Pearson's) between the number of fictional narratives that participants reported to have read and their empathic concern subscale scores. As an entire sample, this association was not significant, $r=0.05, p=0.289$. Here, the magnitude of this relation is practically zero, which was unexpected. Even when the data was split by sex, this same correlation was non-significant for both males, $r=-0.00, p=0.492$, and females, $r=-0.07$, $p=0.296$. Thus, no support for the first subsidiary hypothesis was gathered based on these particular analyses. 


\section{Hypothesis S2: Relation between Primary Caregiver Parenting Style and Hostile Attributions}

Here, it is examined whether a relation exists between the parenting style of the participants' primary caregivers and scores on hostile attribution bias (as measured by the third story stem). Accordingly, this section aims to assess the second subsidiary hypothesis, which predicted that participants who rated their primary caregivers as high in control and low on support would score higher on hostile attribution bias.

\section{Association between primary caregiver perceptions and hostile attribution bias.}

Table S1 on the following page lists the number of participants categorized in each combination of high-low parental control and support. Since only the aggressive driving story stem produced an appreciable number of participants making hostile attributions $(n=58)$, as opposed to benign ones $(n=78)$, attribution bias for the third story stem was used to examine its relation with perceived parenting style. Chi-square analyses were run that compared the proportion of participants in the high control, low support category who produced hostile versus benign attributions, compared to participants from the other three categories. As a whole sample, a nonsignificant effect was found, $\chi^{2}(1)=0.43, p=0.332$. When the data were split by sex, these relations remained non-significant for both males, $\chi^{2}(1)=0.02, p=0.581$, as well as females, $\chi^{2}$ $(1)=0.75, p=0.300$. Thus, no link was found between participants' attribution style (hostile or benign) and their ratings of their primary caregivers (as low in care/high on overprotection versus the other three parenting styles). No support for the second subsidiary hypothesis was seen from these analyses. 
Table S1. Proportion of Perceived Parenting Style Types According to Participant Sex. Parental Bonding Quadrant* Number of Male Number of Female Participants $(n=67)$

(1) Affectionless control (low care/high protection) 12

(2) Neglectful parenting (low care/low protection) 7

(3) Affectionate constraint (high care/high 28 protection)

(4) Optimal parenting (high care/low protection) 20

Participants $(n=69)$

*These categories reflect the participants' perceived parenting style of their primary caregivers. 


\section{References}

Anderson, C. A., \& Bushman, B. J. (2001). Effects of violent video games on aggressive behavior, aggressive cognition, aggressive affect, physiological arousal, and prosocial behavior: A meta-analytic review of the scientific literature. Psychological Science, 12(5), 353-359. doi: 10.1111/1467-9280.00366

Anderson, C. A., Shibuya, A., Ihori, N., Swing, E. L., Bushman, B. J., Sakamoto, A., ... Saleem, M. (2010). Violent video game effects on aggression, empathy, and prosocial behavior in eastern and western countries: A meta-analytic review. Psychological Bulletin, 136(2), 151-173. doi: 10.1037/a0018251

Bal, P. M., \& Veltkamp, M. (2013). How does fiction reading influence empathy? An experimental investigation on the role of emotional transportation. PLoS ONE, 8(1), 1-12. doi: 10.1371/journal.pone.0055341

Bandura, A. (1965). Influence of models' reinforcement contingencies on the acquisition of imitative responses. Journal of Personality and Social Psychology, 1(6), 589-595. doi: $10.1037 / \mathrm{h} 0022070$

Bandura, A. (1978). Social learning theory of aggression. Journal of Communication, 28(3), 1229. doi: 10.1111/j.1460-2466.1978.tb01621.x

Barlett, C. P., Harris, R. J., \& Baldassaro, R. (2007). Longer you play, the more hostile you feel: Examination of first person shooter video games and aggression during video game play. Aggressive Behavior, 33(6), 486-497. doi: 10.1002/ab.20227

Baumeister, R. F., \& Bushman, B. J. (2014). Social psychology and human nature (3rd ed.). Belmont, CA: Wadsworth.

Brizuela, M. A. (2011). The relationship between time playing violent video games and road rage in males. Retrieved from ProQuest Information \& Learning. (AAI3468248) 
Bushman, B. J., \& Anderson, C. A. (2002). Violent video games and hostile expectations: A test of the general aggression model. Personality and Social Psychology Bulletin, 28(12), 1679-1686. doi: 10.1177/014616702237649

Bushman, B. J., \& Anderson, C. A. (2009). Comfortably numb: Desensitizing effects of violent media on helping others. Psychological Science, 20(3), 273-277. doi: 10.1111/j.14679280.2009.02287.x

Davis, M. H. (1980). A multidimensional approach to individual differences in empathy. JSAS Catalog of Selected Documents in Psychology, 10, 85.

Davis, M. H. (1983). Measuring individual differences in empathy: Evidence for a multidimensional approach. Journal of Personality and Social Psychology, 44(1), 113126. doi: 10.1037/0022-3514.44.1.113

Eastin, M. S., \& Griffiths, R. P. (2009). Unreal: Hostile expectations from social gameplay. New Media \& Society, 11(4), 509-531. doi: 10.1177/1461444809102958

Ferguson, C. J. (2008).The school shooting/violent video game link: Causal relationship or moral panic? Journal of Investigative Psychology and Offender Profiling, 5(1-2), 25-37. doi: 10.1002/jip.76

Ferguson, C. J. (2010). Blazing angels or resident evil? Can violent video games be a force for good? Review of General Psychology, 14(2), 68-81. doi: 10.1037/a0018941

Field, A. (2009). Discovering statistics using SPSS (3rd ed.). Thousand Oaks, CA: Sage.

Fischer, P., Greitemeyer, T., Morton, T., Kastenmüller, A., Postmes, T., Frey, D., ... Odenwälder, J. (2009). The racing-game effect: Why do video racing games increase risk-taking inclinations? Personality and Social Psychology Bulletin, 35(10), 1395-1409. doi: 10.1177/0146167209339628 
Fraser, A. M., Padilla-Walker, L. M., Coyne, S. M., Nelson, L. J., \& Stockade, L. A. (2012). Associations between violent video gaming, empathic concern, and prosocial behavior toward strangers, friends, and family members. Journal of Youth and Adolescence, 41(5), 636-649. doi: 10.1007/s10964-012-9742-2

Freedman, J. L. (2002). Media violence and its effect on aggression: Assessing the scientific evidence. Toronto, ON: University of Toronto Press.

Friedrich, L. K., \& Stein, A. H. (1975). Prosocial television and young children: The effects of verbal labeling and role playing on learning and behavior. Child Development, 46(1), 2738. doi: $10.2307 / 1128830$

Gentile, D. A., Anderson, C. A., Yukawa, S., Ihori, N., Saleem, M., Ming, L. M., ... Huesmann, L. R. (2009). The effects of prosocial video games on prosocial behaviors: International evidence from correlational, longitudinal, and experimental studies. Personality and Social Psychology Bulletin, 35(6), 752-763. doi: 10.1177/0146167209333045

Gentile, D. A., Coyne, S., \& Walsh, D. A. (2011). Media violence, physical aggression, and relational aggression in school age children: A short-term longitudinal study. Aggressive Behavior, 37(2), 193-206. doi: 10.1002/ab.20380

Gomez, R., \& Gomez, A. (2000). Perceived maternal control and support as predictors of hostilebiased attribution of intent and response selection in aggressive boys. Aggressive Behavior, 26(2), 155-168. doi: 1002/(SICI)1098-2337(2000)

Gomez, R., Gomez, A., DeMello, L., \& Tallent, R. (2001). Perceived maternal control and support: Effects on hostile biased social information processing and aggression among clinic-referred children with high aggression. Journal of Child Psychology and Psychiatry, 42(4), 513-522. doi: 10.1111/1469-7610.00745 
Greitemeyer, T., \& McLatchie, N. (2011). Denying humanness to others: A newly discovered mechanism by which violent video games increase aggressive behavior. Psychological Science, 22(5), 659-665. doi: 10.1177/0956797611403320

Greitemeyer, T., \& Osswald, S. (2010). Effects of prosocial video games on prosocial behavior. Journal of Personality and Social Psychology, 98(2), 211-221. doi: 10.1037/a0016997

Greitemeyer, T., Osswald, S., \& Brauer, M. (2010). Playing prosocial video games increases empathy and decreases schadenfreude. Emotion, 10(6), 796-802. doi: 10.1037/a0020194

Harris, P., \& Houston, J. (2010). Recklessness in context: Individual and situational correlates to aggressive driving. Environment and Behavior, 42(1), 44-60. doi: $10.1177 / 0013916508325234$

Hartmann, T., \& Vorderer, P. (2010). It's okay to shoot a character: Moral disengagement in violent video games. Journal of Communication, 60(1), 94-119. doi: 10.1111/j.14602466.2009.01459.x

Johnson, S. (2006). Everything bad is good for you: How today's popular culture is actually making us smarter. New York, NY: Riverhead Trade.

Kirsh, S. J. (1998). Seeing the world through Mortal-Kombat-colored glasses: Violent video games and the development of a short-term hostile attribution bias. Childhood, 5(2), 177184. doi: $10.1177 / 0907568298005002005$

Kirsh, S. J., \& Olczak, P. V. (2000). Violent comic books and perceptions of ambiguous provocation situations. Media Psychology, 2(1), 47-62. doi: 10.1207/S1532785XMEP0201_3

Kirsh, S. J., \& Olczak, P. V. (2002). The effects of extremely violent comic books on social information processing. Journal of Interpersonal Violence, 17(11), 1160-1178. doi: $10.1177 / 088626002237400$ 
Kirsh, S. J., Olczak, P. V., \& Mounts, J. R. (2005). Violent video games induce an affect processing bias. Media Psychology, 7(3), 239-250. doi: 10.1207/S1532785XMEP0703_1

Klapper, J. T. (1960). The effects of mass communication. New York, NY: Free Press.

Krahé, B., \& Möller, I. (2004). Playing violent electronic games, hostile attributional style, and aggression-related norms in German adolescents. Journal of Adolescence, 27(1), 53-69. doi: 10.1016/j.adolescence.2003.10.006

Krahé, B., \& Möller, I. (2010). Longitudinal effects of media violence on aggression and empathy among German adolescents. Journal of Applied Developmental Psychology, 31(5), 401-409. doi: 10.1016/j.appdev.2010.07.003

McCrae, R. R. \& Costa, P. T. (2010). NEO personality inventory-3, NEO five-factor inventory-3, and Revised NEO inventory: Professional manual. Lutz, FL: Psychological Assessment.

Möller, I., \& Krahé, B. (2009). Exposure to violent video games and aggression in German adolescents: A longitudinal analysis. Aggressive Behavior, 35(1), 75-89. doi: 10.1002/ab.20290

Orne, M. T. (1962). On the social psychology of the psychological experiment: With particular reference to demand characteristic and their implications. American Psychologist, 17(11), 776-783. doi: 10.1037/h0043424

Paik, H., \& Comstock, G. (1994). The effects of television violence on antisocial behavior: A meta-analysis. Communication Research, 21(4), 516-546. doi: $10.1177 / 009365094021004004$

Parker, G., Tupling, H., \& Brown, L. B. (1979). A parental bonding instrument. British Journal of Medical Psychology, 52(1), 1-10. doi: 10.1111/j.2044-8341.1979.tb02487.x

Pinker, S. (2011). The better angels of our nature: Why violence has declined. New York, NY: Viking. 
Preston, S. D., \& de Waal, F. B. (2002). Empathy: Its ultimate and proximate bases. Behavioral and Brain Sciences, 25(1), 1-72. doi: 10.1017/S0140525X02000018

Road Safety Canada Consulting. (2011). Road safety in Canada (Catalogue No.: T46-54/12011E). Ottawa, ON: Transport Canada.

Salem, S. K. (2010). The effects of pro-social video games on empathy. Retrieved from Chicago Digital Repository. (http://hdl.handle.net/10211.4/114)

Scharrer, E. (2008). Media exposure and sensitivity to violence in news reports: Evidence of desensitization? Journalism \& Mass Communication Quarterly, 85(2), 291-310. doi: $10.1177 / 107769900808500205$

Schechter, H. (2005). Savage pastimes: A cultural history of violent entertainment. New York, NY: St. Martin's Press.

Sharkin, B. S. (2004). Road rage: Risk factors, assessment, and intervention strategies. Journal of Counseling and Development, 82(2), 191-198. doi: 10.1002/j.15566678.2004.tb00301.x

Southwell, B. G., \& Doyle, K. O. (2004). The good, the bad, or the ugly? A multilevel perspective on electronic game effects. American Behavioral Scientist, 48(4), 391-401. doi: $10.1177 / 0002764204270277$

Statistics Canada. (2011). General social survey - 2010: Overview of the time use of Canadians. (Catalogue number 89-647-XWE). Retrieved October 12, 2012 from Statistics Canada: http://www5.statcan.gc.ca/bsolc/olc-cel/olc-cel?lang=eng\&catno=89-647-X

Steinkuehler, C., \& Duncan, S. (2008). Scientific habits of mind in virtual worlds. Journal of Science Education and Technology, 17(6), 530-543. doi: 10.1007/s10956-008-9120-8 
Transport Canada (2011). Road Safety in Canada. (Catalogue number T46-54/1-2011E). Retrieved March 12, 2013 from Transport Canada: http://publications.gc.ca/pub?id=392067\&sl=0

Watson, D., Clark, L. A., \& Tellegen, A. (1988). Development and validation of brief measures of positive and negative affect: The PANAS scales. Journal of Personality and Social Psychology, 54(6), 1063-1070. doi: 10.1037/0022-3514.54.6.1063

Wolf, M. J. (Eds.). (2001). The medium of the video game. Austin, TX: University of Texas Press. 